\title{
Mutations in the EDR1 Gene Alter the Response of Arabidopsis thaliana to Phytophthora infestans and the Bacterial PAMPs flg22 and elf18
}

\author{
Katrin Geissler, ${ }^{1}$ Lennart Eschen-Lippold, ${ }^{1}$ Kai Naumann, ${ }^{1}$ Korbinian Schneeberger, ${ }^{2}$ Detlef Weigel, ${ }^{2}$ \\ Dierk Scheel, ${ }^{1}$ Sabine Rosahl, ${ }^{1}$ and Lore Westphal ${ }^{1}$ \\ ${ }^{1}$ Department of Stress and Developmental Biology, Leibniz Institute of Plant Biochemistry, Weinberg 3, D-06120 Halle \\ (Saale), Germany; ${ }^{2}$ Department of Molecular Biology, Max Planck Institute for Developmental Biology, D-72076 Tübingen, \\ Germany
}

Submitted 25 September 2014. Accepted 20 October 2014.

\begin{abstract}
Mechanistically, nonhost resistance of Arabidopsis thaliana against the oomycete Phytophthora infestans is not well understood. Besides PEN2 and PEN3, which contribute to penetration resistance, no further components have been identified so far. In an ethylmethane sulphonate-mutant screen, we mutagenized pen2-1 and screened for mutants with an altered response to infection by $P$. infestans. One of the mutants obtained, enhanced response to Phytophthora infestans6 (erp6), was analyzed. Whole-genome sequencing of erp6 revealed a single nucleotide polymorphism in the coding region of the kinase domain of At1g08720, which encodes the putative MAPKKK ENHANCED DISEASE RESISTANCE1 (EDR1). We demonstrate that three independent lines with knock-out alleles of edr1 mount an enhanced response to $P$. infestans inoculation, mediated by increased salicylic acid signaling and callose deposition. Moreover, we show that the single amino acid substitution in erp6 causes the loss of in vitro autophosphorylation activity of EDR1. Furthermore, growth inhibition experiments suggest a so-far-unknown involvement of EDR1 in the response to the pathogen-associated molecular patterns flg22 and elf18. We conclude that EDR1 contributes to the defense response of $A$. thaliana against $P$. infestans. Our data position EDR1 as a negative regulator in postinvasive nonhost resistance.
\end{abstract}

Nonhost resistance of a plant species includes multiple preand postinvasive mechanisms that effectively confer resistance against all genotypes of a pathogen (Heath 2000; Mysore and Ryu 2004). The activation of such defense pathways requires

Current address for K. Geissler: Symrise AG, Mühlenfeldstr. 1, D-37603 Holzminden, Germany.

Current address for K. Naumann: Riboxx GmbH, Meissner Str. 191, D01445 Radebeul, Germany.

Current address for K. Schneeberger: Max Planck Institute for Plant Breeding Research, D-50829 Cologne, Germany.

Corresponding author: L. Westphal; E-mail: Lore.Westphal@ipb-halle.de; Telephone: +49 3455582 1432; Fax: +49 34555821409

* The $\boldsymbol{e}$-Xtra logo stands for "electronic extra" and indicates that six supplementary figures and one supplementary tableare published online.

(C) 2015 The American Phytopathological Society the recognition of pathogen-associated molecular patterns (PAMPs) and results in the establishment of PAMP-triggered immunity (PTI). PAMPs are highly conserved molecules of microbes, including epitopes of bacterial flagellin and elongation factor EF-Tu, fungal chitin, and glucan from oomycetes. They are perceived through pattern recognition receptors, which are located in the plant plasma membrane. Two of the best-studied PAMP-receptor pairs comprise flg22, a highly conserved elicitor-active epitope in the $\mathrm{N}$-terminal domain of flagellin, and its receptor FLAGELLIN SENSING2 (FLS2) as well as the EF-Tu RECEPTOR (EFR), which facilitates the recognition of elf18, an 18-amino acid long domain of bacterial EF-Tu (Felix et al. 1999; Kunze et al. 2004; Zipfel et al. 2004, 2006).

Fast defense responses triggered upon PAMP perception comprise the alteration of ion fluxes across the plasma membrane, an oxidative burst and the activation of mitogen-activated protein kinase (MAPK) cascades, whereas the activation of pathogenesis-related gene expression and the deposition of callose represent late reactions (Boller and Felix 2009). PTI can be suppressed by microbial effectors, leading to effectortriggered susceptibility. In turn, additional plant receptors, mainly nucleotide binding-leucine-rich repeat proteins, can directly or indirectly detect these effectors and thereby induce effector-triggered immunity (ETI) (Jones and Dangl 2006). Recent publications indicate that both PTI and ETI contribute to nonhost resistance (Schulze-Lefert and Panstruga 2011; Zhang et al. 2010). Forward and reverse genetic approaches identified several genes important for nonhost resistance in Arabidopsis against the nonadapted biotrophic pathogen Blumeria graminis f. sp. hordei. The penetration mutants are impaired in defense responses induced during the preinvasive stage of infection (Collins et al. 2003; Lipka et al. 2005; Stein et al. 2006). PENETRATION1 (PEN1) encodes SYNTAXIN OF PLANTS 121 (SYP121), which is involved in vesicle trafficking (Assaad et al. 2004; Collins et al. 2003; Kwon et al. 2008). The PEN 2 myrosinase releases potentially antimicrobial metabolites from 4-methoxyindol-3-ylmethylglucosinolate, which are presumably exported into the apoplast by the PEN3/ PLEIOTROPIC DRUG RESISTANCE8 (PDR8) ATP-binding cassette transporter, and might also be involved in defense signaling (Bednarek et al. 2009; Clay et al. 2009; Lipka et al. 2008). One or more of the lipase-like proteins EDS1 (ENHANCED DISEASE SUSCEPTIBILITY1), PAD4 (PHYTOALEXIN DEFICIENT4), and SAG101 (SENESCENCE ASSOCIATED GENE101) were identified as important components 
of postinvasive defense mechanisms against B. graminis f. sp. hordei (Lipka et al. 2005; Stein et al. 2006).

The Arabidopsis gene EDRI (ENHANCED DISEASE RESIS$T A N C E 1)$ encodes a putative MAPK kinase kinase (MAPKKK) with an $\mathrm{N}$-terminal domain of unknown function and a C-terminal kinase domain (Frye et al. 2001). MAPKKK are involved in responses to biotic and abiotic stresses as well as developmental processes (Suarez-Rodriguez et al. 2010). In defense against pathogens, EDR1 functions as a negative regulator of cell death (Frye et al. 2001) as well as a positive regulator of the expression of plant defensins (Hiruma et al. 2011). It has recently been shown that EDR1 tunes defense responses by negatively regulating the MKK4/MKK5-MPK3/MPK6 kinase cascade (Zhao et al. 2014). The direct interaction of EDR1 with MKK4 and MKK5 occurs via the N-terminal domain and does not require the C-terminal kinase domain. Loss-of-function mutants of EDR1 are more resistant to the biotrophic pathogens Golovinomyces cichoracearum (Frye and Innes 1998) and Hyaloperonospora arabidopsidis (van Hulten et al. 2006) but show an enhanced susceptibility to hemibiotrophic Colletotrichum higginsianum and necrotrophic Alternaria brassicicola (Hiruma et al. 2011). These four pathogens are adapted to Arabidopsis and can cause disease on many wild strains of this host. A role of EDR1 in nonhost resistance has been less clear. Zimmerli and associates (2004) observed an enhanced celldeath response of the edrl mutant in response to $B$. graminis $\mathrm{f}$. $\mathrm{sp}$. hordei infection but no increase in fungal growth. Hiruma and associates (2011) showed that EDR1 functions as a positive regulator of preinvasion resistance of Arabidopsis against the hemibiotrophic $C$. gloeosporioides, acting independently of PEN2. The enhancement of invasion on edrl mutants does not depend on salicylic acid (SA) but correlates with a downregulation of plant defensin gene expression. Since constitutive expression of plant defensin PDF 1.2 only partially rescued the $e d r l$ phenotype, an additional, yet-unknown function of EDR1 in penetration resistance was postulated (Hiruma et al. 2011).

$P$. infestans is the causal agent of potato and tomato late blight disease, which leads to severe crop losses worldwide (Fry and Goodwin 1997; Haverkort et al. 2009). P. infestans is a hemibiotrophic oomycete and only adapted to a few solanaceous plant species; it is not able to infect $A$. thaliana. The elucidation of the complex mechanism of nonhost resistance of Arabidopsis against this oomycete might allow the development of new strategies for the control of late blight disease in the host plants potato and tomato and is, therefore, of great agricultural and economic interest. So far, it was shown that nonhost resistance of Arabidopsis against $P$. infestans involves PEN2 and PEN3 but not PEN1, EDS1, PAD4, and SAG101 (Lipka et al. 2005; Westphal et al. 2008). In order to identify additional nonhost resistance components, we performed a forward genetic screen starting with the pen2-1 mutant, which is compromised in resistance to $P$. infestans (Lipka et al. 2005). In this screen, we isolated several double mutants showing an enhanced response to $P$. infestans (erp). The erpl mutant carries a defect in the gene encoding a PHOSPHOLIPID:STEROL ACYLTRANSFERASE (PSAT1), which suggests an involvement of sterol conjugates in nonhost defense responses against P. infestans (Kopischke et al. 2013).

In this paper, we report that another erp mutant, erp6, carries a point mutation in the coding region of the kinase domain of the EDRl gene. Penetration resistance against the nonadapted $P$. infestans is unaltered. The enhanced localized cell death response of $e d r l$ mutants against $P$. infestans includes callose deposition in the mesophyll, suggesting that postinvasive defense reactions are affected. The development of cell death and the deposition of callose are dependent on SA and PMR4/GSL5 (POWDERY MILDEW RESISTANT4/GLUCAN
SYNTHASE-LIKE5), respectively. Furthermore, we report that EDR1 is involved in the defense signaling response of Arabidopsis to the bacterial PAMPs flg22 and elf18.

\section{RESULTS}

Isolation of the enhanced response to $P$. infestans mutant pen2-1 erp6.

The pen2-1 erp6 mutant is one of 14 erp (enhanced response to Phytophthora) mutants that were isolated in a pen $2-1$ background, using $P$. infestans as the pathogen (Kopischke et al. 2013). Its phenotype of enhanced cell death after inoculation with $P$. infestans, as compared with the pen $2-1$ single mutant (Fig. 1A), was verified by quantifying the intensity of trypan blue staining (Fig. 1B). An F2 segregating population was established by crossing pen2-1 erp6 and the Arabidopsis ecotype Landsberg erecta. The analysis of genetic markers and scoring of the cell-death phenotype in F3 lines, which were homozygous for the pen2-1 mutation, indicated that the erp6 mutation is localized on chromosome 1, between the top of the chromosome and the INDEL marker CER458676 $(9,559,825$ bp) (Salathia et al. 2007). Whole-genome resequencing (Ossowski et al. 2008) and comparison of single nucleotide polymorphisms (SNP) of several erp mutants revealed a pen2-1 erp6-specific point mutation in the coding sequence of At1g08720. The SNP introduces a TaqI restriction site into the nucleotide sequence, which allowed the development of an allele-specific CAPS marker (cleaved amplified polymorphic sequence) (Konieczny and Ausubel 1993). For both wild type and the erp6 mutant, a CAPS marker fragment of $750 \mathrm{bp}$ is amplified, with only the amplicon carrying the mutation being digested by TaqI into 498- and 252-bp fragments (Fig. 1C).

The protein encoded by At1g08720 is annotated as the putative MAPKKK EDR1 (The Arabidopsis Information Resource database). The ethylmethane sulphonate-typical nucleotide substitution ( $\mathrm{G}$ to $\mathrm{A}$ ) of the pen2-1 erp6 mutant is located in exon 12 of EDRl and results in an amino acid exchange from glycine to glutamate at position 854 in the kinase domain of the protein (Fig. 1D and E). An erp6 single mutant was selected by backcrossing pen2-1 erp6 to the background wild-type strain Col-3 gll-1, scoring the cell-death response to $P$. infestans in the segregating progeny, and analyzing the pen2-1- and erp6specific CAPS markers for genotypes with the erp6 mutation in the PEN2 wild-type background.

\section{EDR1 is involved in the response of Arabidopsis against $P$. infestans.}

The edrl-1 mutant (Frye and Innes 1998) and the homozygous T-DNA insertion mutant SALK_053889 (edrl-2; Hiruma et al. 2011) responded to inoculation with $P$. infestans with cell death (Fig. 2A) and callose deposition in the mesophyll layer (Fig. 2C). P. infestans structures were not detected in the mesophyll cell layer of $g l 1$, pen2, or $e d r 1$ plants. Macroscopically, the cell-death reaction was barely noticeable 3 days postinoculation (dpi) (Fig. 2A). It was clearly visible 6 days after inoculation, and control inoculation of leaves with water did not lead to development of hypersensitive response-like cell death on any of the lines tested (Supplementary Fig. S1). Quantification of the intensity of trypan blue staining at the inoculation sites confirmed that the cell-death reaction of the $e d r l$ mutants is significantly stronger in comparison with the wild-type plants but is not significantly different between $e d r 1-1, e d r l-2$, and $\operatorname{erp} 6$ (Fig. 2B).

To analyze the loss of EDR1 function in the pen 2 background, the double mutant pen2-1 edrl-2 was generated and the homozygosity confirmed using allele-specific markers. The response of pen2-1 edrl-1 and pen2-1 edr1-2 to P. infestans 
was comparable to that of pen2-1 erp6 (Fig. 2D), which was confirmed by quantitative analysis of trypan blue-stained leaves of six different pen2-1 edr1-2 lines (Supplementary Fig. S2).

To provide further support that the enhanced response of erp6 to $P$. infestans is caused by the EDR1 mutation, pen2-1 edr1-1 was crossed to pen2-1 erp6. Upon inoculation with $P$. infestans, eight $\mathrm{F} 1$ plants exhibited a stronger cell-death reaction in comparison with pen2, indicating that there was no complementation of the double-mutant phenotype. The response of four F1 plants was not significantly different from pen2. However, the corresponding F2 lines were characterized by a significantly stronger trypan blue staining at the inoculation sites and, therefore, revealed that no complementation of the cell-death phenotype had occurred (Supplementary Fig. S3).

The analysis of additional edr1 alleles in the PEN2 and pen 2-1 background as well as the allelism test with two double mutants confirmed that the enhanced response to $P$. infestans phenotype of the erp6 and pen2-1 erp 6 mutant is caused by the point mutation in exon 12 of EDRl. Consequently, the edrl allele of erp6 is renamed to edr1-4, but the designation erp6 is still used for consistency within this paper.

\section{The erp6 mutant possesses EDR1 transcripts but is impaired in EDR1 phosphorylation.}

Since the genetic data implied that erp6 was a loss-of-function allele of $E D R 1$, the impact of the erp6 mutation on the function of EDR1 was addressed. In contrast to $e d r l-1$ and edrl-2, which show a strong reduction of EDRl transcript levels, the amount of EDRI transcripts of erp6 appears to be unaltered compared with wild-type levels (Fig. 3A).
To assess whether the amino acid exchange in the kinase domain of EDR1 affects kinase activity, the kinase domains of the wild-type and mutant EDR1 protein were expressed in Escherichia coli as His-maltose-binding protein (MaBP) fusion proteins. The fusion proteins were purified using metal affinity chromatography and were subsequently subjected to sodium dodecyl sulfate-polyacrylamide gel electrophoresis (SDSPAGE) and staining with a phospho-specific dye. The recombinant protein containing the wild-type kinase domain showed intense staining also in the absence of ATP although to a lesser extent, which is probably due to autophosphorylation already in E. coli or residual ATP from the bacterial lysate and demonstrates the strong autophosphorylation activity (Fig. 3B). No staining, with or without ATP, was observed for the fusion protein containing the mutated kinase domain, indicating the loss of autophosphorylation activity.

To gain additional information on the autophosphorylation activity of both versions of the EDR1 kinase domain, phosphorylation sites were identified by mass spectrometry. For the mutated kinase domain, notably fewer phosphorylation events in comparison with the wild-type version of the protein were detected (Fig. 3C). These observations indicate that the amino acid exchange in the EDR1 kinase domain of erp6 might impair kinase activity and thus causes the complete loss of autophosphorylation.

\section{EDR1 is not involved in preinvasive defense of Arabidopsis against $P$. infestans.}

Recently, Hiruma and associates (2011) reported that edrl-1 shows an impairment in penetration resistance of Arabidopsis against $C$. gloeosporioides, which correlates with the inability
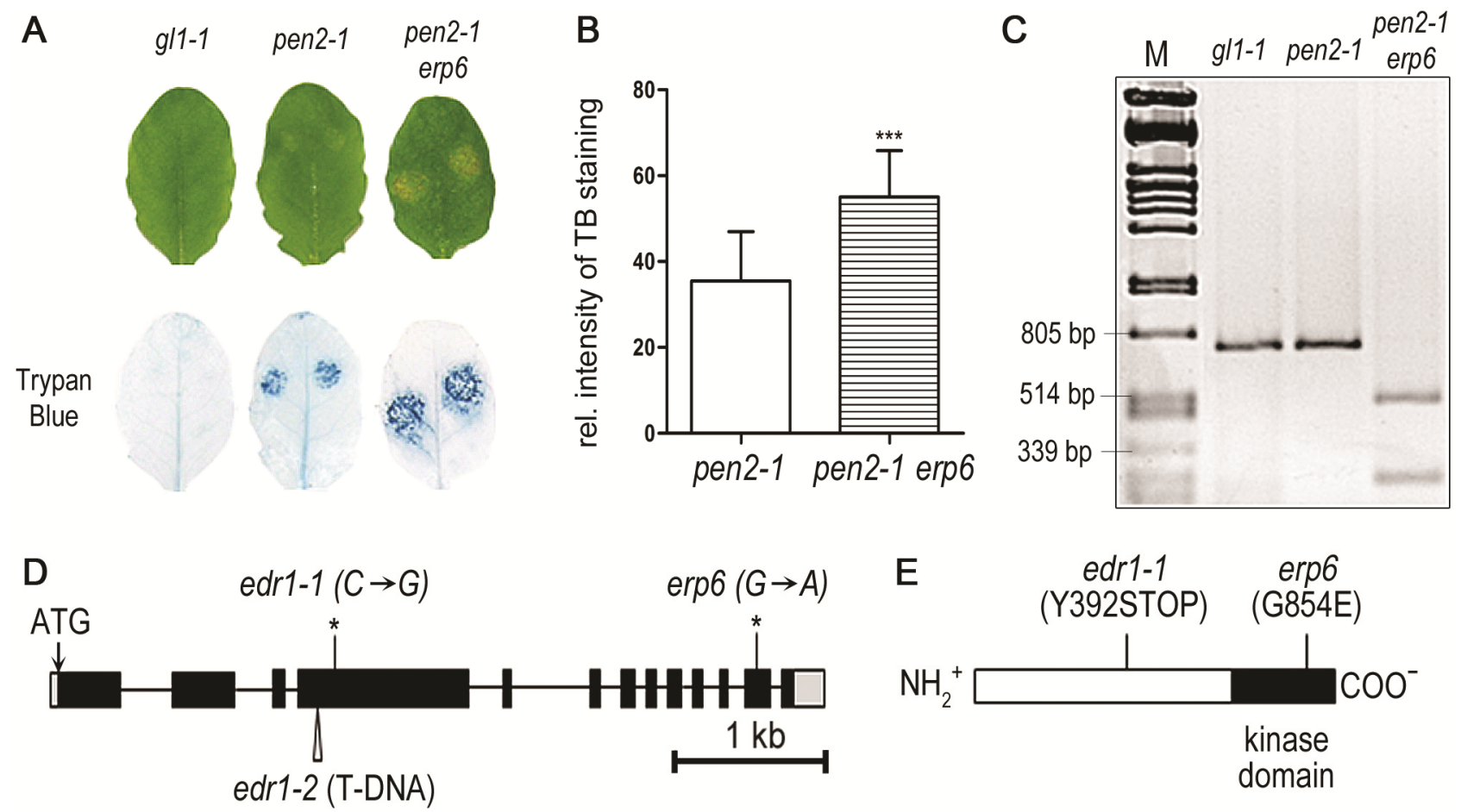

Fig. 1. Phenotype of the pen2-1 erp6 mutant after Phytophthora infestans treatment and location of the edr1 mutation present in erp6. A, Arabidopsis gl1-1, pen2-1, and pen2-1 erp6 plants were grown for 5 weeks. Rosette leaves were drop-inoculated with $P$. infestans $\left(2 \times 10^{4}\right.$ spores per milliliter, $10-\mu 1$ droplets). Photos were taken 3 days postinoculation, and the leaves were subjected to trypan blue (TB) staining for visualization of cell death (lower panel). The displayed leaves represent experiments performed in triplicate. B, Relative intensity of inoculation sites on TB-stained leaves as exemplarily shown in A. Values represent mean \pm standard deviation $(n=29$ to 33$)$. Asterisks indicate significantly different data according to one-way analysis of variance test $(P<0.001)$. The experiment was repeated twice with similar results. C, After performing a cleaved amplified polymorphic sequence-polymerase chain reaction and restriction with TaqI, the 750-bp wild-type fragment is cut into 498- and 252-bp fragments in erp6. D, Intron-exon organization of EDR1 displaying the location of the edr1-1 and erp6 mutations as well as the T-DNA insertion site of edr1-2 (SALK_053889). E, Schematic illustration of the EDR1 protein highlighting the modifications present in edrl-1 and erp6. 
to activate $P D F 1.2$ expression. C. gloeosporioides is a hemibiotrophic fungal pathogen and, like the hemibiotrophic oomycete $P$. infestans, is not adapted to Arabidopsis. To elucidate whether EDR1 is also involved in preinvasive resistance against $P$. infestans, cell death in the epidermal cell layer of single mutants was investigated. Microscopic analysis of trypan blue-stained leaves treated with a high spore concentration revealed differences between the EDRI single mutants (edr1-1, erp6) and the penetration resistance mutant pen2-1 that was used as a control. While pen2-1 leaves displayed the characteristic increase in the number of single cells in the epidermal layer undergoing cell death as described by Lipka and associates (2005), cell death in the edrl single mutants was mainly restricted to the mesophyll layer, and the occurrence of dead epidermal cells was comparable to the situation in wild type (Fig. 2C). These observations were confirmed by quantitative analysis of inoculation sites. In comparison with the controls Col-0 and Col-3 gll-1, the number of dead epidermal cells was significantly higher in pen $2-1$ but not in $e d r 1-1$ and erp6 (Fig. 4A). Analysis of the PDF1.2 transcript levels revealed no significant differences between wild-type plants and the $e d r 1$ mutants (Fig. 4B). These data suggest that EDR1 is rather involved in postinvasive than in penetration resistance of Arabidopsis against $P$. infestans.

\section{The enhanced response of $e d r 1$ mutants} to $P$. infestans requires PMR4/GLS5 and SA.

The response of $e d r l$ mutants to $P$. infestans is confined to the mesophyll layer, in which cell death and massive callose depositions are induced (Fig. 2C). To elucidate the biosynthetic pathways involved in the development of this phenotype, the double mutants edr1-1 sid2-1 and erp6 sid2-1 as well as edrl-1 pmr4-1 were generated and tested with $P$. infestans. SID2 (SALICYLIC ACID INDUCTION DEFICIENT2) encodes

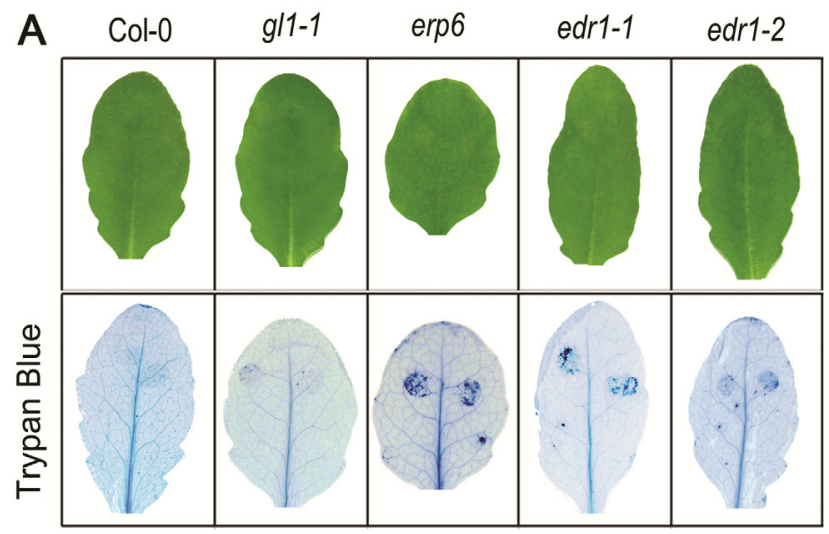

B

C

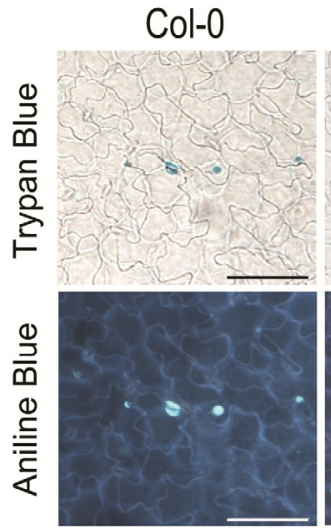

$g / 1-1$

erp6
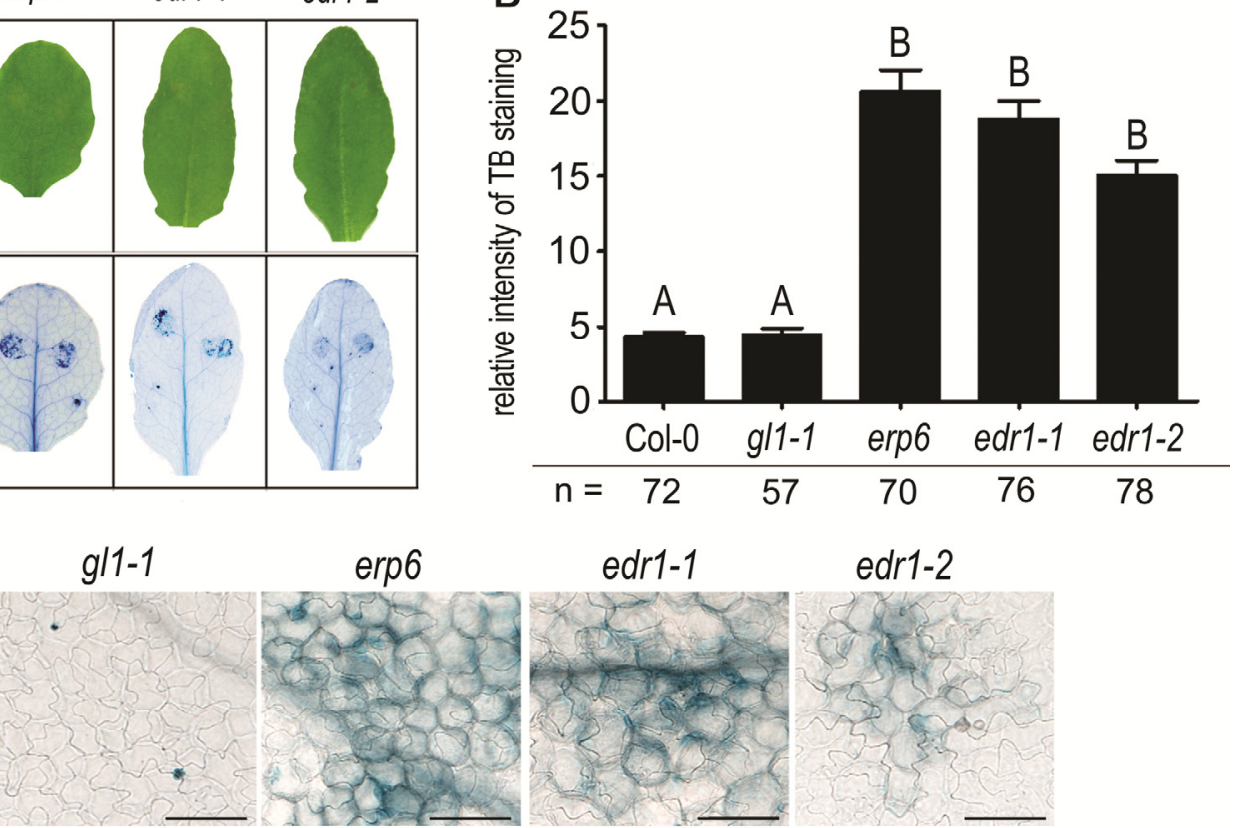

edr1-1

edr1-2
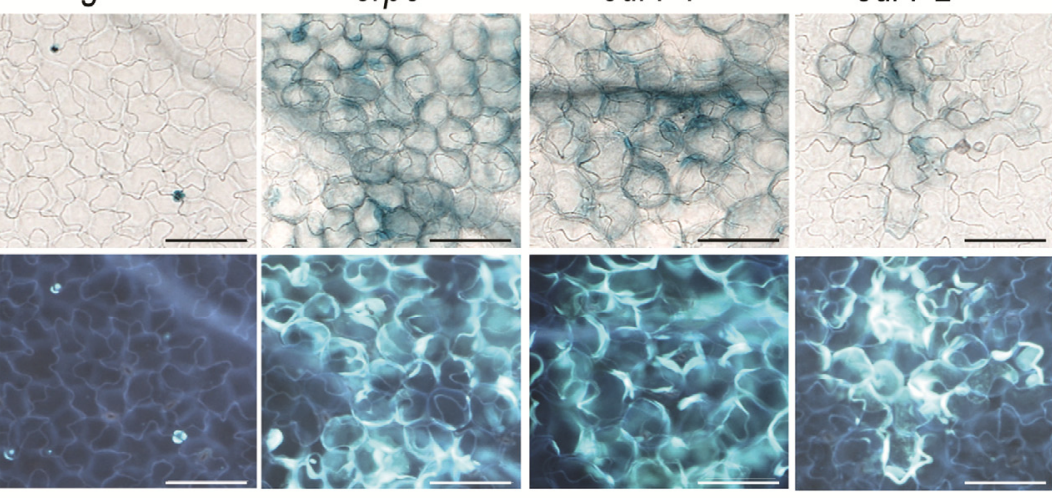

D

pen2-1

pen2-1

pen2-1 x edr1-2

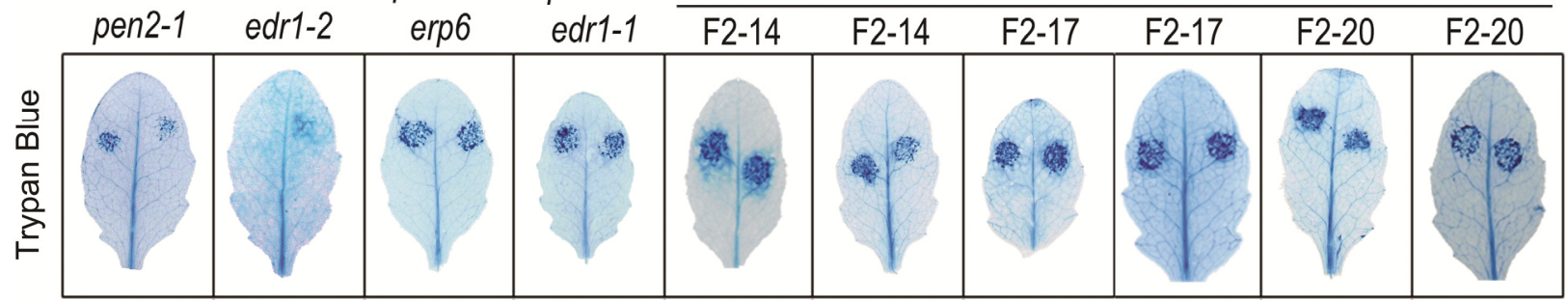

Fig. 2. Phenotype of different EDR1 alleles after Phytophthora infestans inoculation. A, Arabidopsis plants were grown for 5 weeks. Leaves, drop-inoculated with $P$. infestans $\left(5 \times 10^{5}\right.$ spores per milliliter, $10-\mu l$ droplets), were photographed 3 days later and were stained with trypan blue (TB, lower panel). B, Relative intensity of TB staining at inoculation sites of leaves representatively shown in A. Values represent mean + standard error of the mean from two combined experiments (number [n] for each genotype is depicted underneath the columns). Letters indicate significantly different data according to one-way analysis of variance test $(P<0.001)$. C, Leaves of 5-week-old plants were drop-inoculated with $P$. infestans $\left(2 \times 10^{4}\right.$ spores per milliliter, $10-\mu l$ droplets $)$. At 4 days postinoculation, leaves were subjected to a combined staining with TB and aniline blue to visualize cell death and callose. The microscopic pictures were taken using a stereo zoom microscope (Scale bars $=500 \mu \mathrm{m}$ ). D, Control lines and pen2-1 edr1-2 F2 plants were grown for 5 weeks. Rosette leaves were drop-inoculated with $P$. infestans $\left(5 \times 10^{4}\right.$ spores per milliliter, $10-\mu l$ droplets $)$ and were subjected to TB staining 3 days postinoculation. 
isochorismate synthase 1 , which is required for the pathogeninduced synthesis of SA. sid2 mutants accumulate low levels of SA after pathogen infection, as compared with wild-type plants (Wildermuth et al. 2001). PMR4/GSL5 is a callose synthase involved in wound- and pathogen-induced callose formation (Jacobs et al. 2003; Nishimura et al. 2003). While edrl-1 and erp6 single mutant plants showed an enhanced cell-death reaction at the inoculation sites, in both the edrl-1 sid2-1 and erp6 sid2-1 double mutants the wild-type phenotype was restored (Fig. 5A). Quantitative analyses of staining intensity at inoculation sites confirmed the macroscopical observation (Fig. 5B). Although the cell-death response of the edr1-1 pmr4-1 double mutant seen after trypan blue staining was comparable to the reaction of the $e d r l-1$ single mutant, no callose depositions were detectable (Fig. 5C). Thus, the celldeath response of the $e d r l$ mutants to the nonadapted $P$. infestans requires SA. The deposition of callose in the mesophyll layer of $e d r l$ mutants challenged with $P$. infestans depends on PMR4/GSL5.

\section{EDR1 plays a role in responses triggered by the bacterial PAMPs flg22 and elf18.}

To further elucidate the role of EDR1 in defense mechanisms, we addressed its impact on PTI-related responses, which are a major part of nonhost resistance. Since knowledge about influences of Phytophthora PAMPs on the Arabidopsis system is limited and the PAMP Pep-13 was shown to be nonfunctional in Arabidopsis (Gäbler 2007), we decided to use the well-defined bacterial PAMPs flg22 and elf18 (Felix et al.
1999; Kunze et al. 2004). The exogenous application of these peptides to wild-type Arabidopsis seedlings leads to rootgrowth inhibition as well as a reduction of the fresh weight (Gómez-Gómez et al. 1999; Zipfel et al. 2006). Flg22 was used for root-growth inhibition assays on agar plates whereas, in case of elf18, seedling fresh weight was analyzed. In comparison with wild type, all three edrl-mutants were more sensitive to a low concentration of flg22 $(1 \mu \mathrm{M})$. At a concentration of $10 \mu \mathrm{M}$ flg22, root-growth inhibition of only two mutants, erp6 and edr1-2, was significantly higher (Fig. 6A). Possibly, the high concentration of flg22 represents an unphysiological condition masking the biological effect of the PAMP. An inhibitory effect was also observed for the PAMP elf18. The application of $100 \mathrm{nM}$ elf 18 to seedlings grown in liquid culture had a significantly stronger inhibiting effect on the fresh weight of the edrl mutants than on the growth of the Col-0 seedlings (Fig. 6B).

To get a first insight into the potential of the EDR1 kinase domains to influence early PAMP-triggered defense responses, the well-established mesophyll protoplast luciferase (LUC) reporter assay was used (Asai et al. 2002; Boudsocq et al. 2010; Ranf et al. 2011). Protoplasts coexpressing N-terminally hemagglutinin (HA)-tagged EDR1 kinase domain variants and a construct carrying the defense-related NHL10 (NDR1/HIN1-LIKE 10) promoter fused to the Photinus pyralis $L U C$ gene were elicited with the PAMPs flg22 and elf18. In the presence of either EDR1 kinase domain (WT or erp6), an enhanced basal pNHL1O promoter activity was detected (Fig. 7A, $\mathrm{H}_{2} \mathrm{O}$ treatment). Upon PAMP treatment, strongly increased and long-
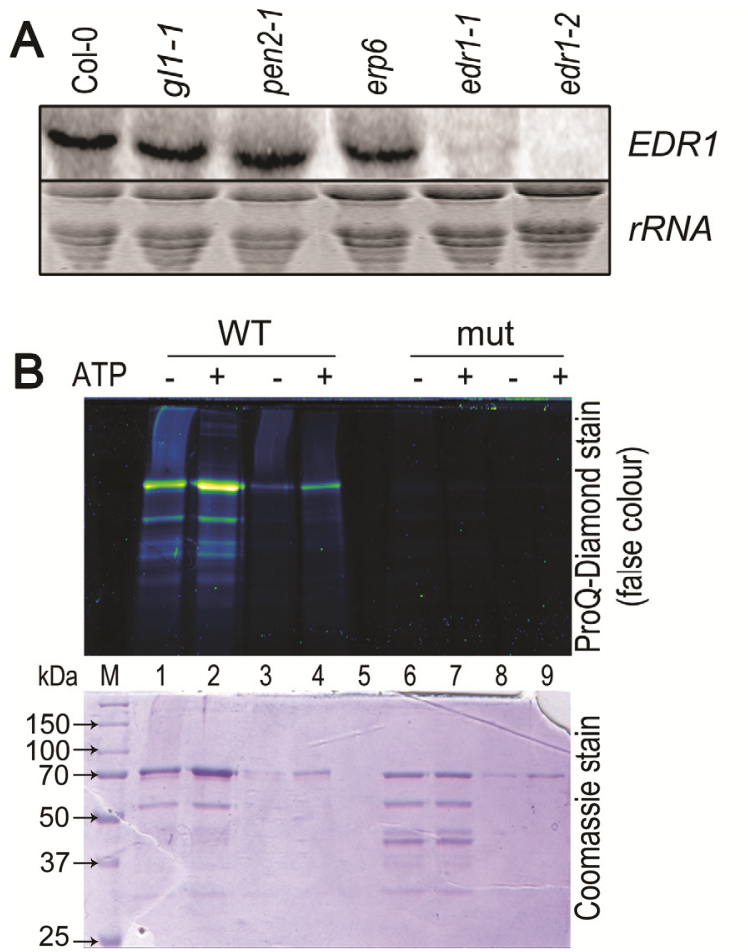

C

$$
\text { Col-0-KD (WT) }
$$

669 LVIAERIGLGSYGEVYHADWHGTEVAVKKFLDQDFSGAAI 709 AEFRSEVRIMRRL RHPNVVFFLGAVTRP PNLSIVTEFL PR

749 GSLYRILHRP KSH IDERRRI KMALDVAMGMNCLHTSTPTI

789 VHRDLKT PNLLVDNNWNVKVGDF GL SRL KHNTFLSSKS TA

829 GTPEWMAPEV LRNEPSNEKCDVYSF GVI LWELATLRL PWR

869 GMNPMQVVGA VGF QNRRLEI PKELD PVVGRI ILECWQT DP 909 NLRPSFAQLTEVLKPLNRLVLPTPQ

\section{erp6-KD (mut)}

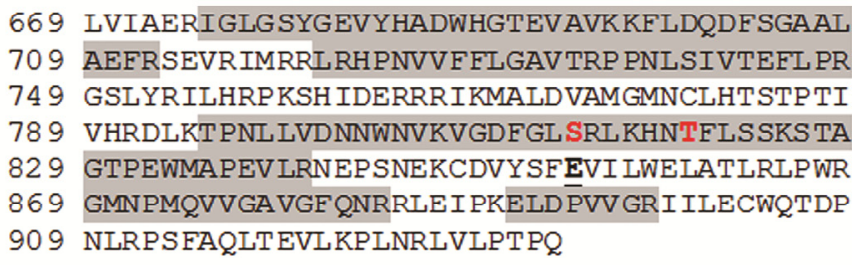

Fig. 3. Northern blot analysis of EDRl transcript levels and autophosphorylation activity of the EDR 1 kinase domain from wild type (WT) and erp6 (mut). A, Total RNA was isolated from untreated 6-week-old plants and was subjected to Northern-blot analysis (20 $\mu \mathrm{g}$ of total RNA per lane) using a radioactively labeled probe of EDR1. The lower panel shows $r R N A$ stained with ethidium bromide to visualize equal loading. B, The kinase domains from WT and the erp6 mutant were recombinantly expressed in Escherichia coli as a fusion protein (approximately $70 \mathrm{kDa}$ ) and were purified using metal affinity chromatography. Following an in vitro kinase assay, the proteins were separated on a polyacrylamide gel under denaturing conditions and were stained with Pro-Q Diamond (upper panel). Coomassie staining of the gel was carried out as a control for equal loading (lower panel). Lanes 1 through 4, EDR1-kinase domain (WT; first elution: lanes 1 and 2; second elution: lanes 3 and 4); lane 5: empty; lanes 6 through 9: EDR1-kinase domain (mut; first elution: lanes 6 and 7; second elution: lanes 8 and 9). C, Proteins analyzed by Pro-Q Diamond and Coomassie blue stain shown in B were cut out and were subjected to trypsin digestion and subsequent liquid chromatography-mass spectrometry analysis for identification of phosphopeptides. Representative results from one of three experiments are shown. Identified peptides are shaded in gray with phosphorylated amino acid residues highlighted in red. The amino acid that is substituted in erp6 is in bold and underlined. 
lasting pNHL10 activity was observed in kinase domain-expressing protoplasts as compared with control samples expressing N-terminally HA-tagged cyan fluorescent protein (CFP) (Fig. 7A). As additional control, protoplasts coexpressing the N-terminally HA-tagged Pseudomonas syringae pv. tomato effector AvrPto, which strongly suppresses PAMP-induced defense gene activation (He et al. 2006) (Fig. 7A), were included in the analyses. In parallel, samples were analyzed by Westernblot to confirm expression of the transformed constructs (Supplementary Fig. S4) and stability of EDR1 kinase-domain variants for the duration of the experiments (Fig. 7B).

Since NHL10 gene expression is upregulated in response to MAPK cascade activation (Boudsocq et al. 2010), we subsequently tested whether the enhanced response observed in the LUC assay was due to earlier or stronger MAPK activation. Mesophyll protoplasts expressing N-terminally HA-tagged EDRl kinase domain variants, $C F P$, or AvrPto were elicited with flg22, and total protein extracts were subjected to Western-blot analyses, using an antibody recognizing the phosphorylated residues within the MAPK activation loop ( $\alpha$-phosphop44/42-ERK [ $p$ TE $p$ Y] motif). There were no differences in timing and intensity of MAPK activation detectable between CFP- or kinase domain variant-expressing samples, whereas MAPK activation was strongly diminished in AvrPto-expressing samples (Fig. 7C).

Taken together, the increased sensitivity of the edrl mutants towards flg22 and elf18 suggests a yet-unknown role of EDR1 in PAMP-triggered immune responses independent or downstream of MAPK activation. Future experiments with transgenic plants expressing EDR1 full length protein versions have to be performed to further elucidate the regulatory mechanisms.

\section{DISCUSSION}

In nonhost interactions between Arabidopsis and nonadapted filamentous pathogens, the first layer of defense is the preinvasive resistance. Initial work to uncover underlying mechanisms at the genetic level identified mutants impaired in penetration gene resistance (pen1, pen2, and pen3) against $B$. graminis $\mathrm{f}$. sp. hordei and Erysiphe pisi (Collins et al. 2003; Lipka et al. 2005; Stein et al. 2006). Characterization of these mutants allowed their assignment to two distinct branches of inducible defense responses effective against nonhost powdery mildew fungi at the cell periphery (Lipka et al. 2008). The PEN1 pathway is functional against nonadapted powdery mildew fungi but not against other filamentous pathogens, such as adapted Plectosphaerella cucumerina, nonadapted P. infestans (Lipka et al. 2005), or both adapted and nonadapted Colletotrichum species (Shimada et al. 2006). The PEN2 pathway, on the other hand, limits growth of a broad spectrum of pathogens (Hiruma et al. 2010; Lipka et al. 2005; Maeda et al. 2009). In this context, EDR1 was described as a new component of preinvasive nonhost resistance against nonadapted $C$. gloeosporioides (Hiruma et al. 2011). The authors showed that edrl mutant plants exhibited an enhanced fungal entry rate as compared with control plants. Our data support the involvement of EDR1 in the nonhost response. Although inoculation with $P$. infestans led to comparable numbers of dead epidermal cells in erp6, edrl-1 and wild-type plants, suggesting that $P$. infestans penetration rates are not elevated in $e d r l$ mutants, the erp6 and edrl mutants displayed drastically enhanced mesophyll cell death, which was accompanied by intense callose deposition in this cell layer (Fig. 2C). A similar situation was observed for B. graminis f. sp. hordei. Infection experiments revealed no increase in hyphal growth but a strongly increased mesophyll cell death (Zimmerli et al. 2004). In the pen2-1 edr1 double mutants, inoculation with $P$. infestans induced an even stronger cell death response (Figs. 1B and 2D; Supplementary Fig. S5). A similar result was described for $C$. gloeosporioides (Hiruma et al. 2011). All these data show that EDR1 functions independently of the PEN2 pathway. In the double mutants, the strength of the mesophyll cell death reaction to $P$. infestans infection impeded the determination of the epidermal cell death rate, and therefore, an enhanced fungal entry rate cannot be ruled out. Nevertheless, these results position EDR1 as a negative regulator in the layer of postinvasive resistance in the nonhost interaction of Arabidopsis with $P$. infestans or $B$. graminis f. sp. hordei, respectively. This hypothesis is supported by the observation that many genes induced in edrl-1 after infection with adapted $G$. cichoracearum encode signaling proteins, indicating that defense signaling induced by pathogen perception is enhanced in the absence of EDR1 (Christiansen et al. 2011). The authors conclude that one possible function of EDR1 is the prevention of unnecessary signaling to confine the recognition of pathogens in situations without an immediate threat. This hypothesis is strengthened by the recent finding that, in the edrl mutant, total protein levels of MPK3/MPK6 and, concomitantly, MPK3/MPK6 activities are elevated, whereas EDR1 overexpression abrogates this effect and also negatively affects MKK4/MKK5 protein levels (Zhao et al. 2014).

Mechanistically, defense against certain pathogen species requires a different hormonal regulation in the plant. The classical view describes an antagonism between the SA and jasmonic acid (JA)/ethylene signaling pathways, with SA being crucial for
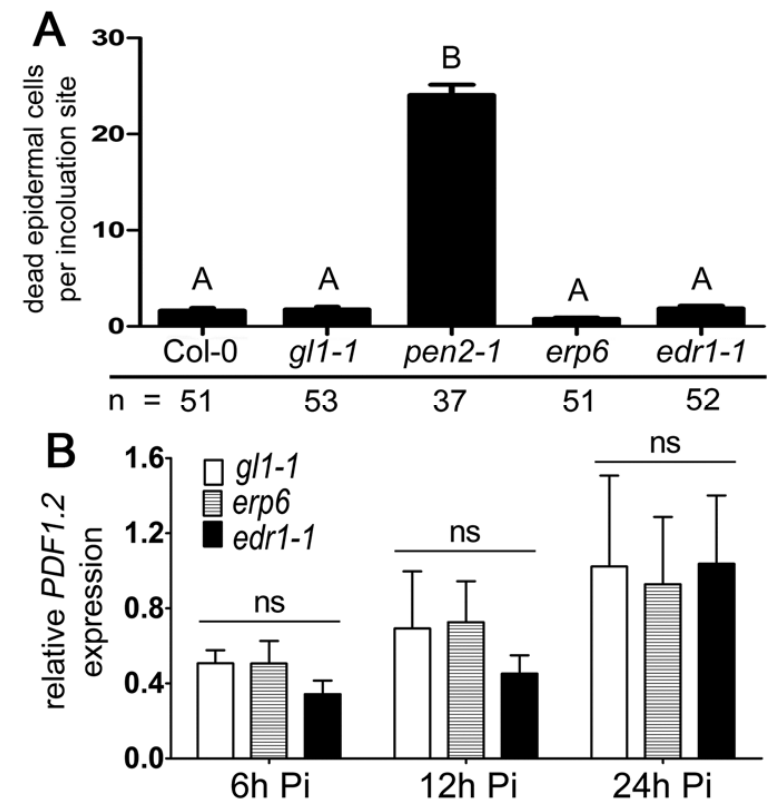

Fig. 4. Analysis of epidermal cell death and PDF1.2 transcript accumulation after Phytophthora infestans inoculation. A, Rosette leaves of 5-weekold Arabidopsis thaliana plants were drop-inoculated with $P$. infestans $(2 \times$ $10^{4}$ spores per milliliter, $10-\mu 1$ droplets) and were stained with trypan blue (TB) 3 days later. Dead epidermal cells were counted per inoculation site in TB-stained samples. Values represent mean + standard error of the mean (SEM) from two combined experiments (number [n] for each genotype depicted underneath the columns). Letters indicate significantly different data according to one-way analysis of variance (ANOVA) test $(P<0.001)$. B, Mutant and control plants were grown for 5 weeks and were dropinoculated with $P$. infestans $\left(\mathrm{Pi}, 5 \times 10^{5}\right.$ spores per milliliter, $10-\mu 1$ droplets). Total RNA was isolated at 6,12 , and $24 \mathrm{~h}$ postinoculation and were subjected to Northern hybridization with radioactively labeled fragments of PDF1.2. Data represent mean + SEM of three combined experiments $(n=$ 6 ). For statistical analysis, a one-way ANOVA was applied (ns = not significantly different). Signal intensities were normalized using the hybridization signal of $r R N A$. 
defense against (hemi-) biotrophic pathogens and JA/ethylene against necrotrophic pathogens. Recent work points to a more complex regulation and interplay, not only between these two pathways but, also, with additional players such as auxin, abscisic acid, cytokinins, gibberellins, and brassinosteroids (Denancé et al., 2013; Derksen et al., 2013; Robert-Seilaniantz et al. 2011). In line with the conventional view, the enhanced cell death response of erp6 sid2-1 and edr1-1 sid2-1 double mutants to hemibiotrophic $P$. infestans was restored to wild-type levels, indicating SA-dependence (Fig. 5A and B). A similar result was obtained in experiments with biotrophic $G$. cichoracearum (Frye et al. 2001), in which the enhanced resistance of $e d r 1$ was not expressed in a SA signaling or accumulation mutant background ( $n p r l, e d s l, N a h G$ ). In contrast, the enhanced lesion phenotype of the $e d r l$ mutant infected with necrotrophic Alternaria brassicicola is SA-independent (Hiruma et al. 2011).

Additional phenotypes of the edrl mutant are reduced growth and spontaneous lesion formation under drought condi- tions, which is also dependent on intact SA signaling (Tang et al. 2005), as well as an ethylene-induced chlorosis phenotype (Frye et al. 2001). In summary, these data suggest a role of EDR1 as a general repressor in stress signaling of both biotic and abiotic origin.

The intense callose deposition in the mesophyll of erp6 and edrl-1 upon $P$. infestans inoculation prompted us to further analyze the underlying regulation. To this end, we made use of the edr1-1 pmr4-1 double mutant described by Wawrzynska and associates (2010). PMR4/GSL5 is known as a pathogenand wound-responsive callose synthase (Jacobs et al. 2003; Nishimura et al. 2003). The edrl pmr4 double mutant was identified in a screen for mutations enhancing the $e d r l$ phenotype. The plants are dwarfed, show a spontaneous formation of necrosis, and constitutive expression of SA- and JA-related genes (Wawrzynska et al. 2010). These phenotypes are reminiscent of the lesion-simulating disease or accelerated cell death mutants, which exhibit a deregulated SA signaling (Dietrich et
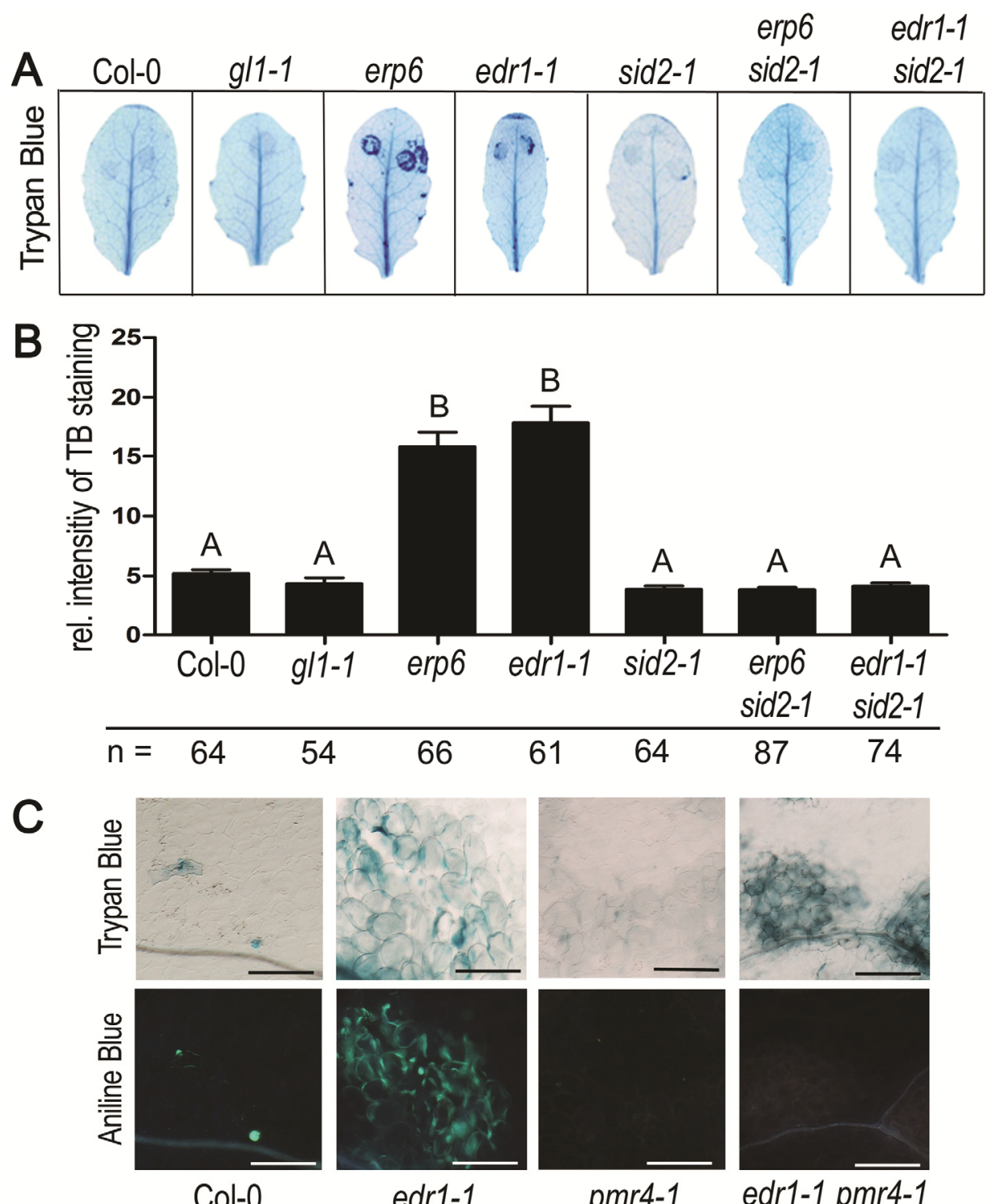

Col-0

edr1-1

pmr4-1

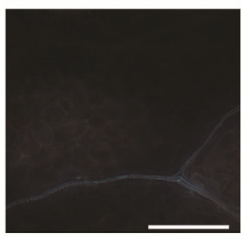

edr1-1 pmr4-1

Fig. 5. Cell death and callose deposition phenotypes of edrl mutants after Phytophthora infestans inoculation. A, Rosette leaves of 5-week-old plants were drop-inoculated with $P$. infestans $\left(5 \times 10^{5}\right.$ spores per milliliter, $10-\mu$ l droplets). Three days later, leaves were stained with trypan blue (TB) to visualize cell death. The experiment was repeated twice with similar results. B, Relative intensity of TB staining at inoculation sites of leaves exemplarily shown in A, analyzed by one-way analysis of variance. Values represent mean + standard error of the mean from three combined experiments (number [n] for each genotype depicted underneath the columns). Letters indicate significantly different data $(P<0.001)$. C, Leaves of 5-week-old plants were drop-inoculated with $P$. infestans $\left(2 \times 10^{4}\right.$ spores per milliliter, $10-\mu$ d droplets $)$. At 4 days postinoculation, leaves were subjected to a combined staining with TB and aniline blue. The microscopic pictures were taken using a stereo zoom microscope (Scale bars $=500 \mu \mathrm{m})$. 
al. 1994; Greenberg et al. 1994; Weymann et al. 1995). These phenotypic characteristics are, however, not present in the edrl and pmr4 single mutants. When inoculated with G. cichoracearum, the edrl pmr4 double mutant displayed enhanced resistance, compared with $e d r 1$ in the absence of callose depositions, accompanied by enhanced cell death (Wawrzynska et al. 2010). Data obtained in our infection experiments with $P$. infestans revealed an enhancement of cell death at the infection sites, without the intense callose depositions seen in the mesophyll of the edrl single mutants (Fig. 5C). Thus, the pmr4/ gsl5 mutation uncouples the enhanced cell-death phenotype from the callose deposition phenotype in the edrl mutants. Furthermore, these results clearly show that PMR4/GSL5 expression alone is responsible for the callose deposition at the $P$. infestans infection sites, despite the presence of more GSL family members in Arabidopsis (Hong et al. 2001; Richmond and Somerville 2000). A similar result was obtained in $G$. cichoracearum-infection experiments described by Vogel and Somerville (2000). The erpl (psat1) mutant, which was identified in the same screen as the erp6 mutant, also shows cell death and callose deposition in the mesophyll layer upon inoculation with $P$. infestans, but the deposition of callose does not depend on PMR4/GSL5 (Kopischke et al. 2013).

Taken together, the regulatory network underlying cell death and callose deposition responses in the $e d r l$ mutant recruits the SA and PMR4/GSL5 pathways, respectively, for both adapted $G$. cichoracearum and nonadapted $P$. infestans.

EDR1 transcript levels in the erp6 mutant are comparable to those in wild type (Fig. 3A), indicating that the loss of EDR1 function is due to inactivation of the protein by the G854E exchange in erp6. In silico motif predictions using PROSITE (Sigrist et al. 2010) showed that neither the ATP-binding domain nor the active pocket are affected by the mutation (Supplementary Fig. S6). However, the alignment of the EDR1 kinase domain with those of the five Arabidopsis EDR1 homologs indicates a localization of the affected amino acid in a highly conserved region of the EDR1 protein (Frye et al. 2001). Kinase assays and the analysis of phosphopeptides using both recombinant kinase domains revealed that the erp6 variant has lost autophosphorylation activity (Fig. 3B). This observation points to a changed kinase activity of the EDR1 protein in erp6, which might interfere with the activation and phosphorylation of downstream EDR1 substrates.

In growth assays, edrl mutants show a higher sensitivity to the PAMPs flg22 and elf18 (Fig. 6). This could be due to enhanced MAPK activation upon receptor-mediated PAMP and pathogen perception. In this context, Zhao and associates (2014) showed enhanced activation of MPK3 and MPK6 in the edrl mutant infected with $P$. syringae pv. tomato DC3000 and G. cichoracearum, respectively. Generally, MAPK cascade activation represents an early defense-related response occurring within minutes (Colcombet and Hirt 2008). Since the EDR1 protein has been annotated as a putative MAPKKK and the kinase activity has been confirmed in phosphorylation experiments with the artificial substrate myelin basic protein (Tang and Innes 2002), we addressed whether EDR1 is involved in early defense-related MAPK signaling. The MAPK MPK3, MPK4, MPK6, and MPK11 are all activated upon flg22 treatment (Bethke et al. 2012). Overexpression of wild-type or erp6 kinase domains alone in Arabidopsis wild-type mesophyll protoplasts had no influence on the activation of these MAPK upon treatment with flg22 or elf18 (Fig. 7C). In the edrl knock-out on the other hand, enhanced MPK3/MPK6 activity was shown, due to elevated total MPK3/MPK6 protein levels in these plants. This effect was reverted in $e d r l$ plants expressing a genomic EDRl construct under control of the endogenous promoter (Zhao et al. 2014). In this context, it is interesting to note that, although expression of EDR1 kinase domain variants alone had no effect on MAPK activation in the transient protoplast system (Fig. 7C), both tested kinase domains enhanced basal promoter activity as well as total promoter activity upon PAMP-treatment in the LUC reporter assay (Fig. 7A). Since this effect was observed for both kinase domain variants, it is independent of the EDR1 (auto)phosphorylation activity. This result suggests either a positive regulatory role of EDR1 in the defense signaling network leading to defenserelated gene expression, which is in contrast to the suppressor function discussed above, or more likely indicates that overexpression of the kinase domains alone disturbs endogenous EDR1 function, leading to a dominant negative effect. A similar phenomenon was observed by Tang and associates (2005). Here, conditional overexpression of the EDR1 kinase domain in Col-0 led to phenotypes like those in the edrl mutant, that is enhanced powdery mildew resistance and enhanced ethyleneinduced chlorosis.

\section{MATERIALS AND METHODS}

\section{Plant material and growth conditions.}

pen2-1 erp6 (in the Col-3 gll-1 background) was identified in a screen described by Kopischke and associates (2013). The edrl-1 allele (Tang and Innes 2002) was obtained from R.
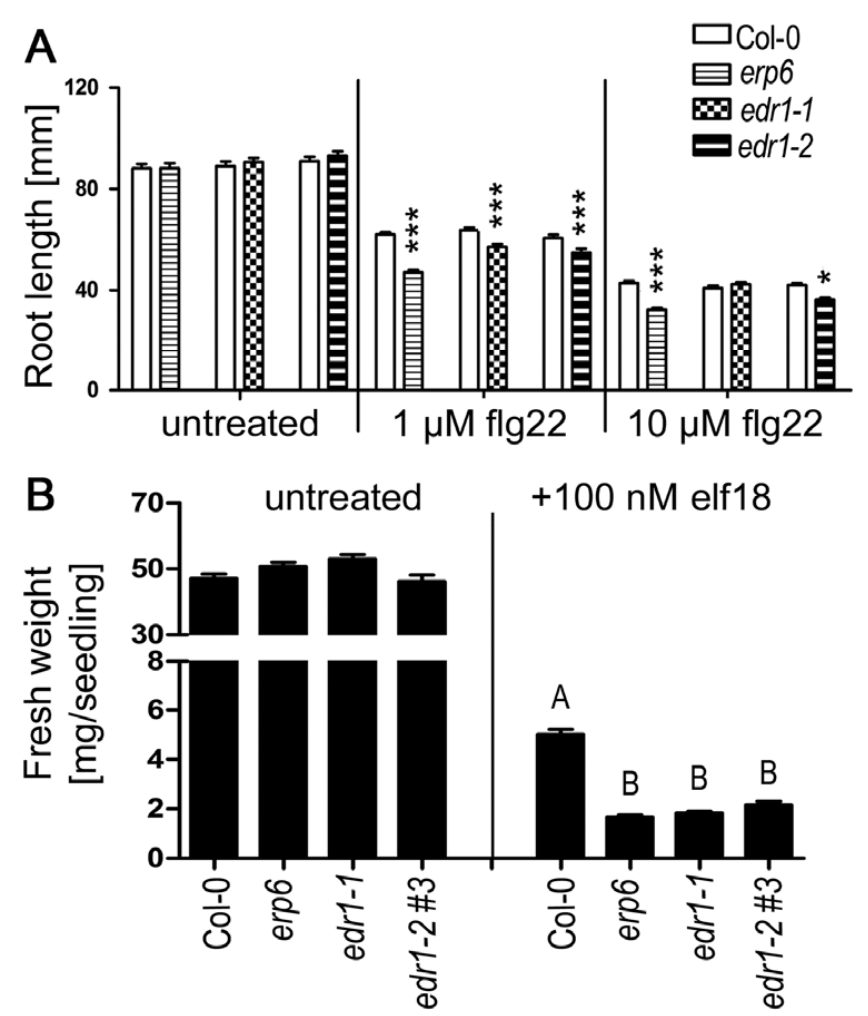

Fig. 6. Analysis of $e d r 1$ mutants in response to flg22 and elf 18 treatments. A, Seeds were germinated on Arabidopsis thaliana medium + sucrose (ATS) plates, and subsequently, 5-day-old seedlings were transferred onto ATS plates without flg22 (untreated) or with $1 \mu \mathrm{M}$ or $10 \mu \mathrm{M}$ flg22, respectively. After 9 days, the root length of the seedlings was determined. Columns represent mean + standard error of the mean (SEM) of three combined experiments $(n=72)$. Asterisks indicate statistically significant differences of the mutant compared with Arabidopsis Col-0 according to two-way analysis of variance (ANOVA) $(*=P<0.05 ; * * *=P<0.001)$. B, Five-day-old seedlings were transferred from ATS plates into 24-well plates with liquid medium containing no elf18 (untreated) or $100 \mathrm{nM}$ elf18. After 13 days, the fresh weight of each seedling was determined. Data are presented as mean + SEM of three combined experiments $(n=$ 72). Different letters indicate statistically significant differences according to one-way ANOVA $(P<0.001)$. 
Innes (University of Indiana, Bloomington, U.S.A.) and edr1-2 (SALK_053889) from the SALK T-DNA collection (Alonso et al. 2003) at the Nottingham Arabidopsis Stock Center. Both mutants have a Col-0 background. pen2-1 (Lipka et al. 2005), gll-1, and pen2-1 edrl-1 were obtained from V. Lipka (University of Göttingen, Germany). To generate the pen2-1 edr1-2 double mutant, pen 2-1 was crossed with edr1-2, and F2 plants with a strong cell-death response to $P$. infestans were selected and their genotype verified using polymerase chain reaction (PCR). edr1-1 sid2, erp6 sid2-1, and edrl-1 pmr4-1 were generated by crossing edr1-1 and erp6 with sid2-1 (Nawrath and Métraux 1999) and pmr4-1 (Vogel and Somerville 2000), respectively. Primers and enzymes used for genotyping of plants are listed in Supplementary Table S1.

Plants for P. infestans experiments, RNA and protein isolation, were cultivated in climate chambers under short day conditions $\left(22^{\circ} \mathrm{C} ; 8 \mathrm{~h}\right.$ light, $16 \mathrm{~h}$ darkness $)$ for 4 to 6 weeks. For experiments with PAMPs elf18 and flg22 (Felix et al. 1999; Kunze et al. 2004), seeds were surface-sterilized as described previously (Ranf et al. 2012), were sowed onto Arabidopsis thaliana medium + sucrose (ATS) agar plates (Estelle and Somerville 1987), and were cultivated under long-day conditions (20 to $22^{\circ} \mathrm{C}, 16 \mathrm{~h}$ light, $8 \mathrm{~h}$ darkness) for 5 days.

\section{Treatment of plants.}

Infection experiments were performed with $P$. infestans CRA208m2 (Si-Ammour et al. 2003) on 4-week-old plants. After cultivating the plants under long-day conditions $(16 \mathrm{~h}$ light, $8 \mathrm{~h}$ darkness) at 20 to $22^{\circ} \mathrm{C}$, leaves were drop-inoculated with a suspension of zoospores in water $\left(2 \times 10^{4}, 5 \times 10^{4}\right.$, or $5 \times 10^{5}$ zoospores per milliliter) and were kept at $100 \%$ humidity for the duration of the experiment.

For elf18 treatment, seedlings were transferred from plates to liquid Murashige Skoog media $(0.5 \times$ Murashige Skoog, $0.25 \%$ sucrose, and $1 \mathrm{mM}$ morpholineethanesulfonic acid, $\mathrm{pH}$
5.7) with or without $100 \mathrm{nM}$ elf18 in 24-well plates (one seedling per well) and were kept under long-day conditions (20 to $22^{\circ} \mathrm{C}, 16 \mathrm{~h}$ light, $8 \mathrm{~h}$ darkness). After 13 days, the fresh weight per seedling was measured. For flg22 treatment, seedlings were placed on square ATS agar plates containing 0,1 , or 10 $\mu \mathrm{M}$ flg22 and were vertically cultivated under long-day conditions (20 to $22^{\circ} \mathrm{C}, 16 \mathrm{~h}$ light, $8 \mathrm{~h}$ darkness). The root length was measured 9 days after transfer. elf 18 and flg 22 were synthesized using an Abimed EPS221 system.

\section{Mapping and sequencing.}

An F2 population was generated from the cross of pen2-1 erp6 with the Arabidopsis ecotype Landsberg erecta. F2 plants were drop-inoculated with $P$. infestans zoospores $\left(5 \times 10^{5}\right.$ zoospores per milliliter), and plants showing a cell-death phenotype (3 dpi) were selfed. DNA for marker analysis was isolated from either leaves of $\mathrm{F} 2$ plants, pools of seedlings of the corresponding F3 lines, or both. For each chromosome, two to five genetic markers (SNP, INDELs) were genotyped. In all, 34 F3 lines homozygous for the pen2-1 mutation were inoculated with $P$. infestans zoospores $\left(5 \times 10^{4}\right.$, one to five experiments per line, 16 to 72 plants per experiment). The cell-death response was scored macroscopically 3 dpi in comparison with the controls $g l 1$, pen2-1, and pen2-1 erp6 and was used to deduce the ERP6 genotype of the corresponding F2 plant. Whole-genome sequencing of the erp6 mutant was performed on an Illumina Genome Analyzer GAIIx. After filtering, 22.7 million 80-bp read pairs were aligned against the reference sequence, resulting in an average genome coverage of 20.5. Consensus calling was performed with the short-read analysis pipeline SHORE (Ossowski et al. 2008) with default parameters.

\section{Staining methods.}

Trypan blue staining of infected leaves to visualize cell death was performed according to Keogh and associates

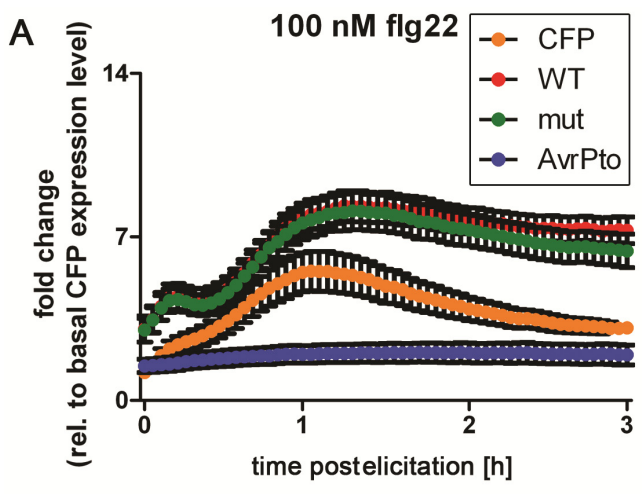

B

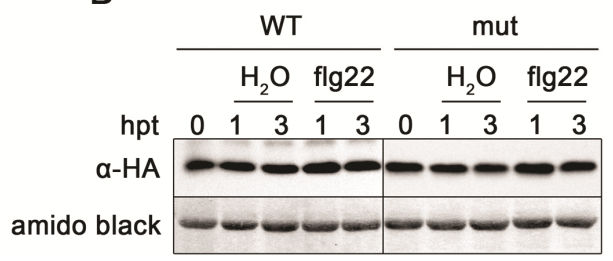

$100 \mathrm{nM}$ elf18

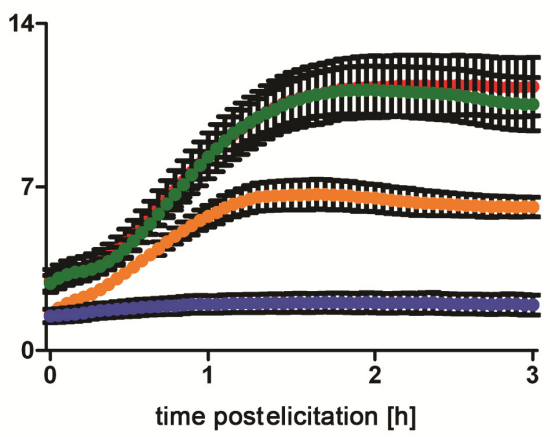

C

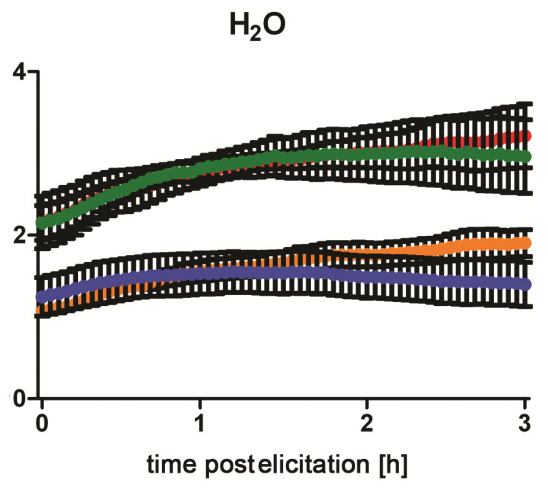

$100 \mathrm{nM}$ flg22

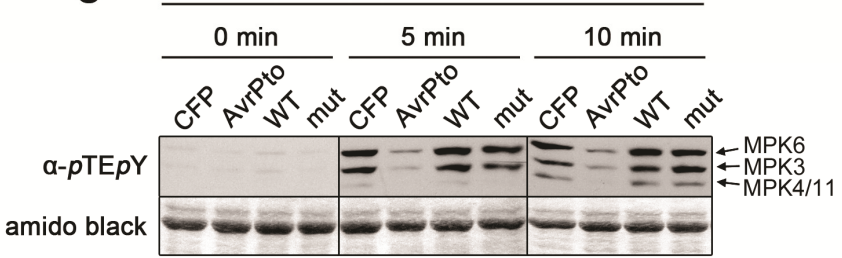

Fig. 7. EDR1 kinase domain overexpression in Arabidopsis protoplasts leads to enhanced defense-related promoter activity. A, B, and C, Arabidopsis thaliana Col-0 protoplasts were co-transformed with pNHL10-LUC (luciferase) as reporter, the p35S-HA-EDR1 kinase domain constructs (Col-0: WT; erp6: mut), $p 35 S-H A-C F P$ and $p 35 S-H A-A v r P t o$ as controls, and $p U B Q 10-G U S$ ( $\beta$-glucuronidase) for normalization. After overnight incubation, protoplasts were treated with either $100 \mathrm{nM}$ flg22, $100 \mathrm{nM}$ elf18, or water as a control. LUC activity was measured for $3 \mathrm{~h}$. Results are depicted as LUC/GUS ratios (A, time point zero of $\mathrm{H}_{2} \mathrm{O}$-treated cyan fluorescent protein sample set at a reference value of one). $\mathbf{B}$, In parallel, independent protoplast aliquots were elicited with $100 \mathrm{nM}$ flg22 or water as a control and protein extracts of samples taken 1 and $3 \mathrm{~h}$ after treatment were analyzed by immunoblotting using a hemagglutinin (HA)-antibody. C, Protoplast aliquots were elicited with $100 \mathrm{nM}$ flg22 and protein extracts of samples taken 0,5 , and 10 min after treatment were analyzed by immunoblotting, using an anti- $p$ TE $p$ Y antibody for detection of activated mitogen-activated protein kinases. The experiments were performed three times with similar results. 
(1980). The staining intensity of inoculation sites was quantitatively analyzed using the ImageJ software. The background staining in close vicinity to the inoculation site was used for correction. For callose staining, aniline blue was used in combination with trypan blue (Ham et al. 2007). Fluorescence microscopy images were taken using a Nikon AZ100 stereo zoom microscope with the UV filter combination $370 / 360 \mathrm{~nm}$ for the excitation filter, $400 \mathrm{~nm}$ (LP) for the dichromatic mirror and $405 \mathrm{~nm}$ (LP) for the barrier filter.

\section{Northern hybridization.}

To analyze the endogenous EDRl transcript levels, total RNA was isolated from leaves of 6-week-old untreated plants using the TRIZOL method (Chomczynski and Sacchi 2006). Northern blots were hybridized with a radioactively labeled fragment of EDRl (At1g08720). The fragment was generated by PCR amplification using the primers 5'-ATCCTGGGACG CTTATACCC-3' and 5'-CTTAAGCCTCGGATCACAGC-3' and were subsequently labeled with $[\alpha]-{ }^{32} \mathrm{P}-\mathrm{dATP}$ using the Amersham Megaprime DNA labeling system.

\section{Construction of EDR1 kinase domain expression clones.}

The kinase domain of EDR1 comprises the amino acid residues 658 to 933 . The corresponding coding sequence was amplified from Col-0 as well as erp6 cDNA (primers: 5'-GATGT TGGTGAATGTGAAATTCCTT-3'， 5'-CTATTGTGGTGTAG GAAGTACAAGCCGG-3') and was cloned in frame with the $\mathrm{C}$-terminus of the MaBP into the expression vector $p D E S T$ N112 (N-terminally $10 \times$ His-tagged; Dyson et al. 2004) using the Gateway technology (Invitrogen).

\section{Expression and purification of recombinant EDR1-kinase domains.}

The fusion protein constructs were transformed into $E$. coli Rosetta-gami cells (Novagen). Protein expression was induced by $1 \mathrm{mM}$ isopropyl- $\beta$-D-thiogalactoside for at least $16 \mathrm{~h}$ at $18^{\circ} \mathrm{C}$. Cells were collected and were suspended in lysis buffer (0.1 $\mathrm{M} \mathrm{NaHPO}_{4} \mathrm{pH} 8 ; 300 \mathrm{mM} \mathrm{NaCl} ; 10 \mathrm{mM}$ imidazole) containing $1 \mathrm{mM}$ phenylmethylsulfonyl fluoride. Cell lysis was performed by adding lysozyme $(1 \mathrm{mg} / \mathrm{ml})$, incubating on ice, and applying ultrasound $(10 \times$ for $1 \mathrm{~s}$ at $60 \%$ amplitude; SONOPULS). DNaseI $(5 \mu \mathrm{g} / \mathrm{ml})$ and Triton X $100(1 \%)$ were added to promote lysis. For protein purification, the lysate was subjected to metal ion affinity chromatography using a HisTrap HP column (GE Healthcare). The purified protein was subsequently analyzed using SDS-PAGE.

\section{Kinase assays and analysis of phosphorylation status.}

Purified fusion proteins containing the EDR1 kinase domain of Col-0 and erp6 were subjected to a nonradioactive autophosphorylation assay in $20 \mu \mathrm{l}$ of kinase buffer $(20 \mathrm{mM}$ HEPES, $15 \mathrm{mM} \mathrm{MgCl}_{2}, 5 \mathrm{mM}$ EGTA, $1 \mathrm{mM}$ dithiothreitol [DTT]). Reactions were incubated with or without $20 \mu \mathrm{M}$ ATP at $37^{\circ} \mathrm{C}$ for $30 \mathrm{~min}$ and were stopped by adding $5 \mu \mathrm{l}$ of SDS loading buffer (0.125 M Tris, pH 6.8; 4\% SDS, 20\% glycerol, $2 \% \beta$-mercaptoethanol, $0.05 \%$ bromophenol blue), followed by boiling for $5 \mathrm{~min}$. Samples were separated on a 10\% SDS polyacrylamide gel that was stained with Pro-Q Diamond phosphoprotein gel stain (Life Technologies) as specified by the manufacturer. Visualization of phosphorylated proteins was achieved by scanning the gel at $580 \mathrm{~nm}$ using a Typhoon 9400 phosphorimager (GE Life Sciences).

\section{In-gel trypsin digestion} of the recombinant kinase domain of EDR1.

For in-gel trypsin digestion following protein isolation, SDS-PAGE and Coomassie brilliant blue R-250 (CBB) stain- ing, protein bands were cut out, were washed twice with water, and were destained with $30 \%$ acetonitrile $(\mathrm{ACN})$ in $100 \mathrm{mM}$ $\mathrm{NH}_{4} \mathrm{HCO}_{3}$ for $15 \mathrm{~min}$. Destaining was repeated until complete removal of $\mathrm{CBB}$, followed by two washing steps with doubledistilled water. The proteins were reduced by incubation with $10 \mathrm{mM}$ DTT in $100 \mathrm{mM} \mathrm{NH}_{4} \mathrm{HCO}_{3}$ for $5 \mathrm{~min}$ at room temperature and $30 \mathrm{~min}$ at $50^{\circ} \mathrm{C}$ and were subsequently incubated in $\mathrm{ACN}$ for $15 \mathrm{~min}$. Alkylation was performed with freshly prepared $54 \mathrm{mM}$ indole 3-acetic acid in $100 \mathrm{mM} \mathrm{NH}_{4} \mathrm{HCO}_{3}$ for 15 min at room temperature in the dark, followed by two washes with $100 \mathrm{mM} \mathrm{NH}_{4} \mathrm{HCO}_{3}$ and $30 \% \mathrm{ACN}$.

The gel fragments were dried in a vacuum centrifuge and were subjected to an overnight digestion in trypsin solution (3 $\mathrm{ng} / \mu \mathrm{l}$ in $10 \mathrm{mM} \mathrm{NH} \mathrm{NCO}_{3}$ and $5 \% \mathrm{ACN}$; modified trypsin from Promega). Supernatant was transferred to a fresh tube and the gel fragments were incubated with extraction solution (35\% ACN and $0.4 \%$ TFA in water). The combined supernatants were dried in a vacuum centrifuge. Peptides were dissolved in $20 \mu \mathrm{l} 0.1 \%$ trifluoroacetic acid (TFA) for $5 \mathrm{~min}$ in an ultrasonic bath and were stored at $-20^{\circ} \mathrm{C}$ until liquid chromatography tandem mass spectrometry (LC-MS/MS) analysis.

\section{Protein sequencing and phosphorylation site determination by LC-MS.}

Tryptic digests were analyzed on a LC-MS system consisting of a split-free nano-LC (Easy-nLC II, Proxeon, Thermo Scientific) coupled to a hybrid-FT-mass spectrometer (LTQ Orbitrap Velos, Thermo Scientific). Peptide separations were performed on a C18 column (Easy column, $10 \mathrm{~cm}$, ID $75 \mu \mathrm{m}$,

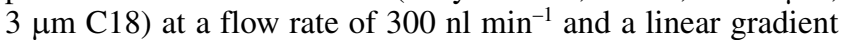
from 2 to $40 \%$ B in 30 min (A: $0.1 \%$ formic acid in water, B: $0.1 \%$ formic acid in $\mathrm{ACN})$. A nanoelectrospray voltage of $+1.90 \mathrm{kV}$ (Nanospray Flex Ion Source with stainless steel emitter [ES542] [Thermo Scientific]) and a capillary temperature of $275^{\circ} \mathrm{C}$ were used for peptide ionization. Data-dependent acquisition was performed by excluding singly charged ions. Precursor masses were scanned from 400 to $1,850 \mathrm{~m} / \mathrm{z}$ in the Orbitrap analyzer, with a resolution of 30,000, and up to 20 precursors were selected per MS scan for subsequent collision induced decay fragmentation in the linear ion trap (mass range: 50 to $2,000 \mathrm{~m} / \mathrm{z}$, scan rate: normal). Targeted LC-MS measurements were performed to analyze low- and high-scoring phosphopeptides using an inclusion list based on previous discrete dipole approximation experiments. Here, peptide fragmentation was achieved either by MS/MS or multistage activation.

Raw data were processed using Proteome Discoverer software (v1.3, Thermo Fisher Scientific) and were searched with an inhouse Mascot server (v2.3.02, Matrix Science) against an Arabidopsis thaliana protein database based on TAIR 10, using an MS tolerance of $10 \mathrm{ppm}$ and MS/MS tolerance of $0.8 \mathrm{Da}$. In addition, oxidized methionine and serine/threonine phosphorylation were chosen as dynamic modifications, whereas carbamidomethylation of cysteine was set as static modification. Scaffold Q+ and Scaffold PTM software (v3.4.9 and v1.1.3, Proteome Software) were used for further data evaluation.

\section{Transient expression in protoplasts.}

Isolation and transformation of protoplasts were performed according to Yoo and associates (2007). For LUC assays, protoplasts were transformed with either $p U G W 15-E D R I$ (WT, from Col-0), $p U G W 15-E D R 1$ (mut, from erp6), $p U G W 15-C F P$ (cyan fluorescent protein), or pUGW15-AvrPto (all N-terminally HAtagged) (Nakagawa et al. 2007). As a reporter, the pNHL10promoter-LUC construct was used (Boudsocq et al. 2010; Ranf et al. 2011). $p U B Q 10-G U S$ was co-transformed for normalization (Norris et al. 1993). Protoplast suspensions containing Dluciferin $(200 \mu \mathrm{M}$ [Invitrogen]) were treated with either 100 
$\mathrm{nM}$ flg22, $100 \mathrm{nM}$ elf18, or water as a control, and luminescence was recorded in 96-well plates for $3 \mathrm{~h}$ (Luminoskan Ascent 2.1; Thermo Scientific). Results are expressed as LUC/ GUS ratios relative to untreated controls.

For immunoblot analyses, protoplast samples were treated with $100 \mathrm{nM}$ flg22 or water as a control. Samples were taken at the indicated timepoints and total protein extracts were subjected to Western blot analyses using anti-HA.11 (Covance) and anti- $p$ TE $p Y$ (Cell Signalling) antibodies. Blots were stained with Amido black as loading control.

\section{Statistical analyses.}

Statistical analyses were performed using GraphPad Prism 5 (Graphpad).

\section{In silico motif prediction.}

The PROSITE database online tool was used for conserved protein domain prediction (Sigrist et al. 2010).

\section{Multiple sequence alignment.}

The complete sequences of EDR1 orthologs from selected plant species were aligned using the PRALINE software (Simossis and Heringa, 2005) by applying the algorithms DSSP (Kabsch and Sander 1983) and PSIPRED (Jones 1999).

\section{ACKNOWLEDGMENTS}

This work was supported by the Deutsche Forschungsgemeinschaft within the Priority Program 1212. L. Eschen-Lippold is supported by the BMBF ProNET-T3 program (03ISO2211B). The authors thank F. Mauch (University of Fribourg, Switzerland) for providing the $P$. infestans isolate CRA208m2, as well as R. Innes (Indiana University; edr1-1), V. Lipka (University of Göttingen, Germany; pen2-1 edr1-1), S. Somerville (University of California, Berkeley, U.S.A.; pmr4-1), C. Nawrath (University of Lausanne, Switzerland; sid2), and the SALK Institute (T-DNA insertion lines) for providing Arabidopsis seeds. We also thank M. Häußler for technical assistance.

\section{LITERATURE CITED}

Alonso, J. M., Stepanova, A. N., Leisse, T. J., Kim, C. J., Chen, H., Shinn, P., Stevenson, D. K., Zimmerman, J., Barajas, P., Cheuk, R., Gadrinab, C., Heller, C., Jeske, A., Koesema, E., Meyers, C. C., Parker, H., Prednis, L., Ansari, Y., Choy, N., Deen, H., Geralt, M., Hazari, N., Hom, E., Karnes, M., Mulholland, C., Ndubaku, R., Schmidt, I., Guzman, P., AguilarHenonin, L., Schmid, M., Weigel, D., Carter, D. E., Marchand, T. Risseeuw, E., Brogden, D., Zeko, A., Crosby, W. L., Berry, C. C., and Ecker, J. R. 2003. Genome-wide insertional mutagenesis of Arabidopsis thaliana. Science 301:653-657.

Asai, T., Tena, G., Plotnikova, J., Willmann, M. R., Chiu, W. L., GomezGomez, L., Boller, T., Ausubel, F. M., and Sheen, J. 2002. MAP kinase signalling cascade in Arabidopsis innate immunity. Nature 415:977-983.

Assaad, F. F., Qiu, J. L., Youngs, H., Ehrhardt, D., Zimmerli, L., Kalde, M., Wanner, G., Peck, S. C., Edwards, H., Ramonell, K., Somerville, C. R., and Thordal-Christensen, H. 2004. The PEN1 syntaxin defines a novel cellular compartment upon fungal attack and is required for the timely assembly of papillae. Mol. Biol. Cell 15:5118-5129.

Bednarek, P., Pislewska-Bednarek, M., Svatos, A., Schneider, B., Doubsky, J., Mansurova, M., Humphry, M., Consonni, C., Panstruga, R., Sanchez-Vallet, A., Molina, A., and Schulze-Lefert, P. 2009. A glucosinolate metabolism pathway in living plant cells mediates broadspectrum antifungal defense. Science 323:101-106

Bethke, G., Pecher, P., Eschen-Lippold, L., Tsuda, K., Katagiri, F., Glazebrook, J., Scheel, D., and Lee, J. 2012. Activation of the Arabidopsis thaliana mitogen-activated protein kinase MPK11 by the flagellin-derived elicitor peptide flg22. Mol Plant Microbe Interact 25:471480.

Boller, T., and Felix, G. 2009. A renaissance of elicitors: perception of microbe-associated molecular patterns and danger signals by patternrecognition receptors. Annu. Rev. Plant Biol. 60:379-406.

Boudsocq, M., Willmann, M. R., McCormack, M., Lee, H., Shan, L., He, P., Bush, J., Cheng, S. H., and Sheen, J. 2010. Differential innate immune signalling via $\mathrm{Ca}^{2+}$ sensor protein kinases. Nature 464:418-422.

Chomczynski, P., and Sacchi, N. 2006. The single-step method of RNA isolation by acid guanidinium thiocyanate-phenol-chloroform extraction: Twenty-something years on. Nature Protocols 1:581-585.

Christiansen, K. M., Gu, Y. N., Rodibaugh, N., and Innes, R. W. 2011. Negative regulation of defence signalling pathways by the EDR1 protein kinase. Mol. Plant Pathol. 12:746-758.

Clay, N. K., Adio, A. M., Denoux, C., Jander, G., and Ausubel, F. M. 2009. Glucosinolate metabolites required for an Arabidopsis innate immune response. Science 323:95-101.

Colcombet, J., and Hirt, H. 2008. Arabidopsis MAPKs: A complex signalling network involved in multiple biological processes. Biochem. J. 413:217-226

Collins, N. C., Thordal-Christensen, H., Lipka, V., Bau, S., Kombrink, E., Qiu, J. L., Hückelhoven, R., Stein, M., Freialdenhoven, A., Somerville, S. C., and Schulze-Lefert, P. 2003. SNARE-protein-mediated disease resistance at the plant cell wall. Nature 425:973-977.

Denancé, N., Sánchez-Vallet, A., Goffner, D., and Molina, A. 2013. Disease resistance or growth: the role of plant hormones in balancing immune responses and fitness costs. Front. Plant Sci. 4:1-12.

Derksen, H., Rampitsch, C., and Daayf, F. 2013. Signaling cross-talk in plant disease resistance. Plant Sci. 207:79-87.

Dietrich, R. A., Delaney, T. P., Uknes, S. J., Ward, E. R., Ryals, J. A., and Dangl, J. L. 1994. Arabidopsis mutants simulating disease resistance response. Cell 77:565-577.

Dyson, M., Shadbolt, S. P., Vincent, K., Perera, R., and McCafferty, J. 2004. Production of soluble mammalian proteins in Escherichia coli: Identification of protein features that correlate with successful expression. BMC Biotechnol. 4:32.

Estelle, M. A., and Somerville, C. 1987. Auxin-resistant mutants of Arabidopsis thaliana with an altered morphology. Mol. Gen. Genet. 206:200-206.

Felix, G., Duran, J. D., Volko, S., and Boller, T. 1999. Plants have a sensitive perception system for the most conserved domain of bacterial flagellin. Plant J. 18:265-276.

Fry, W. E., and Goodwin, S. B. 1997. Resurgence of the Irish potato famine fungus. Bioscience 47:363-371.

Frye, C. A., and Innes, R. W. 1998. An Arabidopsis mutant with enhanced resistance to powdery mildew. Plant Cell 10:947-956.

Frye, C. A., Tang, D., and Innes, R. W. 2001. Negative regulation of defense responses in plants by a conserved MAPKK kinase. Proc. Natl. Acad. Sci. U.S.A. 98:373-378.

Gäbler, Y. 2007. Identification and characterization of PAMP-inducible genes in Petroselinum crispum and Arabidopsis thaliana. Ph.D. dissertation. http://hdl.handle.net/10900/49096. University of Tübingen, Germany.

Gómez-Gómez, L., Felix, G., and Boller, T. 1999. A single locus determines sensitivity to bacterial flagellin in Arabidopsis thaliana. Plant $\mathrm{J}$ $18: 277-284$.

Greenberg, J. T., Guo, A. L., Klessig, D. F., and Ausubel, F. M. 1994. Programmed cell-death in plants-A pathogen-triggered response activated coordinately with multiple defense functions. Cell 77:551-563.

Ham, J. H., Kim, M. G., Lee, S. Y., and Mackey, D. 2007. Layered basal defenses underlie non-host resistance of Arabidopsis to Pseudamonas syringae pv. phaseolicola. Plant J. 51:604-616.

Haverkort, A. J., Struik, P. C., Visser, R. G. F., and Jacobsen, E. 2009. Applied biotechnology to combat late blight in potato caused by Phytophthora Infestans. Potato Res. 52:249-264.

He, P., Shan, L., Lin, N. C., Martin, G. B., Kemmerling, B., Nürnberger, T., and Sheen, J. 2006. Specific bacterial suppressors of MAMP signaling upstream of MAPKKK in Arabidopsis innate immunity. Cell 125:563-575.

Heath, M. C. 2000. Nonhost resistance and nonspecific plant defenses. Curr. Opin. Plant Biol. 3:315-319.

Hiruma, K., Nishiuchi, T., Kato, T., Bednarek, P., Okuno, T., SchulzeLefert, P., and Takano, Y. 2011. Arabidopsis ENHANCED DISEASE RESISTANCE 1 is required for pathogen-induced expression of plant defensins in nonhost resistance, and acts through interference of MYC2-mediated repressor function. Plant J. 67:980-992.

Hiruma, K., Onozawa-Komori, M., Takahashi, F., Asakura, M., Bednarek, P., Okuno, T., Schulze-Lefert, P., and Takano, Y. 2010. Entry modedependent function of an indole glucosinolate pathway in Arabidopsis for nonhost resistance against anthracnose pathogens. Plant Cell 22:2429-2443.

Hong, Z. L., Delauney, A. J., and Verma, D. P. S. 2001. A cell plate specific callose synthase and its interaction with phragmoplastin. Plant Cell 13:755-768.

Jacobs, A. K., Lipka, V., Burton, R. A., Panstruga, R., Strizhov, N., Schulze-Lefert, P., and Fincher, G. B. 2003. An Arabidopsis callose synthase, GSL5, is required for wound and papillary callose formation. Plant Cell 15:2503-2513.

Jones, D. T. 1999. Protein secondary structure prediction based on position-specific scoring matrices. J. Mol. Biol. 292:195-202. 
Jones, J. D. G., and Dangl, J. L. 2006. The plant immune system. Nature 444:323-329.

Kabsch, W., and Sander, C. 1983. Dictionary of protein secondary structure-Pattern-recognition of hydrogen-bonded and geometrical features. Biopolymers 22: 2577-2637

Keogh, R. C., Deverall, B. J., and Mcleod, S. 1980. Comparison of histological and physiological-responses to Phakopsora pachyrhizi in resistant and susceptible soybean. T. Brit. Mycol. Soc. 74:329-333.

Konieczny, A., and Ausubel, F. M. 1993. A procedure for mapping Arabidopsis mutations using codominant ecotype-specific PCR-based markers. Plant J. 4:403-410.

Kopischke, M., Westphal, L., Schneeberger, K., Clark, R., Ossowski, S., Wewer, V., Fuchs, R., Landtag, J., Hause, G., Dörmann, P., Lipka, V., Weigel, D., Schulze-Lefert, P., Scheel, D., and Rosahl, S. 2013. Impaired sterol ester synthesis alters the response of Arabidopsis thaliana to Phytophthora infestans. Plant J. 73:456-468.

Kunze, G., Zipfel, C., Robatzek, S., Niehaus, K., Boller, T., and Felix, G. 2004. The $\mathrm{N}$ terminus of bacterial elongation factor Tu elicits innate immunity in Arabidopsis plants. Plant Cell 16:3496-3507.

Kwon, C., Neu, C., Pajonk, S., Yun, H.S., Lipka, U., Humphry, M., Bau, S., Straus, M., Kwaaitaal, M., Rampelt, H., El Kasmi, F., Jürgens, G., Parker, J., Panstruga, R., Lipka, V., and Schulze-Lefert, P. 2008. Co-option of a default secretory pathway for plant immune responses. Nature 451:835-840

Lipka, U., Fuchs, R., and Lipka, V. 2008. Arabidopsis non-host resistance to powdery mildews. Curr. Opin. Plant Biol. 11:404-411.

Lipka, V., Dittgen, J., Bednarek, P., Bhat, R., Wiermer, M., Stein, M., Landtag, J., Brandt, W., Rosahl, S., Scheel, D., Llorente, F., Molina, A., Parker, J., Somerville, S., and Schulze-Lefert, P. 2005. Pre- and postinvasion defenses both contribute to nonhost resistance in Arabidopsis. Science 310:1180-1183.

Maeda, K., Houjyou, Y., Komatsu, T., Hori, H., Kodaira, T., and Ishikawa, A. 2009. AGB1 and PMR5 contribute to PEN2-mediated preinvasion resistance to Magnaporthe oryzae in Arabidopsis thaliana. Mol. PlantMicrobe Interact. 22:1331-1340.

Mysore, K. S., and Ryu, C. M. 2004. Nonhost resistance: how much do we know? Trends Plant Sci. 9:97-104.

Nakagawa, T., Kurose, T., Hino, T., Tanaka, K., Kawamukai, M., Niwa, Y., Toyooka, K., Matsuoka, K., Jinbo, T., and Kimura, T. 2007. Development of series of gateway binary vectors, pGWBs, for realizing efficient construction of fusion genes for plant transformation. J. Biosci. Bioeng. 104: $34-41$

Nawrath, C., and Métraux, J. P. 1999. Salicylic acid induction-deficient mutants of Arabidopsis express PR-2 and PR-5 and accumulate high levels of camalexin after pathogen inoculation. Plant Cell 11:1393-1404.

Nishimura, M. T., Stein, M., Hou, B. H., Vogel, J. P., Edwards, H., and Somerville, S. C. 2003. Loss of a callose synthase results in salicylic acid-dependent disease resistance. Science 301:969-972.

Norris, S. R., Meyer, S. E., and Callis, J. 1993. The intron of Arabidopsis thaliana polyubiquitin genes is conserved in location and is a quantitative determinant of chimeric gene-expression. Plant Mol. Biol. 21:895906

Ossowski, S., Schneeberger, K., Clark, R. M., Lanz, C., Warthmann, N., and Weigel, D. 2008. Sequencing of natural strains of Arabidopsis thaliana with short reads. Genome Res. 18:2024-2033.

Ranf, S., Eschen-Lippold, L., Pecher, P., Lee, J., and Scheel, D. 2011. Interplay between calcium signalling and early signalling elements during defence responses to microbe- or damage-associated molecular patterns. Plant J. 68:100-113.

Ranf, S., Grimmer, J., Pöschl, Y., Pecher, P., Chinchilla, D., Scheel, D., and Lee, J. 2012. Defense-related calcium signaling mutants uncovered via a quantitative high-throughput screen in Arabidopsis thaliana. Mol. Plant 5:115-130.

Richmond, T. A., and Somerville, C. R. 2000. The cellulose synthase superfamily. Plant Physiol. 124:495-498.

Robert-Seilaniantz, A., Grant, M., and Jones, J. D. G. 2011. Hormone crosstalk in plant disease and defense: More than just JASMONATESALICYLATE antagonism. Ann. Rev. Phytopathol. 49:317-343.

Salathia, N., Lee, H. N., Sangster, T. A., Morneau, K., Landry, C. R., Schellenberg, K., Behere, A. S., Gunderson, K. L., Cavalieri, D., Jander, G., and Queitsch, C. 2007. Indel arrays: An affordable alternative for genotyping. Plant J. 51:727-737.

Schulze-Lefert, P., and Panstruga, R. 2011. A molecular evolutionary concept connecting nonhost resistance, pathogen host range, and pathogen speciation. Trends Plant Sci. 16:117-125.

Shimada, C., Lipka, V., O'Connel, R., Okuno, T., Schulze-Lefert, P., and Takano, Y. 2006. Nonhost resistance in Arabidopsis-Colletotrichum interactions acts at the cell periphery and requires actin filament function. Mol. Plant-Microbe Interact. 19:270-279.
Si-Ammour, A., Mauch-Mani, B., and Mauch, F. 2003. Quantification of induced resistance against Phytophthora species expressing GFP as a vital marker: beta-aminobutyric acid but not BTH protects potato and Arabidopsis from infection. Mol. Plant Pathol. 4:237-248.

Sigrist, C. J. A., Cerutti, L., de Castro, E., Langendijk-Genevaux, P. S., Bulliard, V., Bairoch, A., and Hulo, N. 2010. PROSITE, a protein domain database for functional characterization and annotation. Nucleic Acids Res. 38:D161-D166.

Simossis, V. A., and Heringa, J. 2005. PRALINE: A multiple sequence alignment toolbox that integrates homology-extended and secondary structure information. Nucleic Acids Res. 33:W289-W294.

Stein, M., Dittgen, J., Sanchez-Rodriguez, C., Hou, B. H., Molina, A., Schulze-Lefert, P., Lipka, V., and Somerville, S. 2006. Arabidopsis PEN3/PDR8, an ATP binding cassette transporter, contributes to nonhost resistance to inappropriate pathogens that enter by direct penetration. Plant Cell 18:731-746.

Suarez-Rodriguez, M. C., Petersen, M., and Mundy, J. 2010. Mitogen-activated protein kinase signaling in plants. Ann. Rev. Plant Biol. 61:621649.

Tang, D. Z., and Innes, R. W. 2002. Overexpression of a kinase-deficient form of the EDR1 gene enhances powdery mildew resistance and ethylene-induced senescence in Arabidopsis. Plant J. 32:975-983.

Tang, D. Z., Christiansen, K. M., and Innes, R. W. 2005. Regulation of plant disease resistance, stress responses, cell death, and ethylene signaling in Arabidopsis by the EDR1 protein kinase. Plant Physiol. 138:1018-1026.

van Hulten, M., Pelser, M., van Loon, L. C., Pieterse, C. M. J., and Ton, J. 2006. Costs and benefits of priming for defense in Arabidopsis. Proc. Natl. Acad. Sci. U.S.A. 103:5602-5607.

Vogel, J., and Somerville, S. 2000. Isolation and characterization of powdery mildew-resistant Arabidopsis mutants. Proc. Natl. Acad. Sci. U.S.A. 97:1897-1902.

Wawrzynska, A., Rodibaugh, N. L., and Innes, R. W. 2010. Synergistic activation of defense responses in Arabidopsis by simultaneous loss of the GSL5 callose synthase and the EDR1 protein kinase. Mol. PlantMicrobe Interact. 23:578-584.

Westphal, L., Scheel, D., and Rosahl, S. 2008. The coil-16 mutant harbors a second site mutation rendering PEN2 nonfunctional. Plant Cell 20:824-826.

Weymann, K., Hunt, M., Uknes, S., Neuenschwander, U., Lawton, K., Steiner, H. Y., and Ryals, J. 1995. Suppression and restoration of lesion formation in Arabidopsis Isd mutants. Plant Cell 7:2013-2022.

Wildermuth, M. C., Dewdney, J., Wu, G., and Ausubel, F. M. 2001. Isochorismate synthase is required to synthesize salicylic acid for plant defence. Nature 414:562-565.

Ye, S., Dhillon, S., Ke, X. Y., Collins, A. R., and Day, I. N. M. 2001. An efficient procedure for genotyping single nucleotide polymorphisms. Nucleic Acids Res. 29:-e88.

Yoo, S. D., Cho, Y. H., and Sheen, J. 2007. Arabidopsis mesophyll protoplasts: a versatile cell system for transient gene expression analysis. Nat. Protoc. 2:1565-1572.

Zhang, J., Lu, H.B ., Li, X. Y., Li, Y., Cui, H. T., Wen, C. K., Tang, X. Y., $\mathrm{Su}, \mathrm{Z}$., and Zhou, J. M. 2010. Effector-triggered and pathogen-associated molecular pattern-triggered immunity differentially contribute to basal resistance to Pseudomonas syringae. Mol. Plant-Microbe Interact. 23:940-948.

Zhao C. Z., Nie H. Z., Shen Q. J., Zhang S. Q., Lukowitz W., Tang D. Z 2014. EDR1 physically interacts with MKK4/MKK5 and negatively regulates a MAP kinase cascade to modulate plant innate immunity. Plos Genet. 10:e1004389. doi: 10.1371/journal.pgen.1004389. Pulished online.

Zimmerli, L., Stein, M., Lipka, V., Schulze-Lefert, P., and Somerville, S. 2004. Host and non-host pathogens elicit different jasmonate/ethylene responses in Arabidopsis. Plant J. 40:633-646.

Zipfel, C., Robatzek, S., Navarro, L., Oakeley, E. J., Jones, J. D. G., Felix, G., and Boller, T. 2004. Bacterial disease resistance in Arabidopsis through flagellin perception. Nature 428:764-767.

Zipfel, C., Kunze, G., Chinchilla, D., Caniard, A., Jones, J. D. G., Boller, T., and Felix, G. 2006. Perception of the bacterial PAMP EF-Tu by the receptor EFR restricts agrobacterium-mediated transformation. Cell 125:749-760

\section{AUTHOR-RECOMMENDED INTERNET RESOURCES}

The Arabidopsis Information Resource (TAIR) database: www.arabidopsis.org

ImageJ software: rsb.info.nih.gov/ij

Nottingham Arabidopsis Stock Center website: www.arabidopsis.info 